\title{
A Streptococcus quorum sensing system enables suppression of innate immunity
}

Kate Rahbari ${ }^{+}$, Jennifer Chang ${ }^{\#}$, Michael Federle*\#

+Department of Microbiology and Immunology; University of Illinois at Chicago, Chicago, IL, 60607; USA

"Department of Pharmaceutical Sciences; University of Illinois at Chicago, Chicago, IL, 60607; USA

*Correspondence: mfederle@uic.edu

Running title: GAS QS suppresses innate immunity

Keywords: Immunosuppression, innate immunity, macrophage, pheromone, biosynthetic gene cluster, NFkB, TLR, cytokines 
Abstract: Some bacterial pathogens utilize cell-cell communication systems, such as quorum sensing (QS), to coordinate genetic programs during host colonization and infection. The human-restricted pathosymbiont Streptococcus pyogenes (Group A Streptococcus, GAS) uses the Rgg2/Rgg3 QS system to modify the bacterial surface, enabling biofilm formation and lysozyme resistance. Here, we demonstrate that innate immune cell responses to GAS are substantially altered by the QS status of the bacteria. We found that macrophage activation, stimulated by multiple agonists and assessed by cytokine production and NFKB activity, was substantially suppressed upon interaction with QS-active GAS but not QS-inactive bacteria. Neither macrophage viability nor bacterial adherence were seen as different between QS activity states, yet TNF $\alpha$, IL-6, and IFN $\beta$ levels and NFאB reporter activity were drastically lower following infection with QS-active GAS. Suppression required contact between viable bacteria and macrophages. A QS-regulated biosynthetic gene cluster (BGC) in the GAS genome, encoding several putative enzymes, was also required for macrophage modulation. Our findings suggest a model wherein upon contact with macrophages, QSactive GAS produce a BGC-derived factor capable of suppressing inflammatory responses. The suppressive capability of QS-active GAS is abolished after treatment with a specific QS inhibitor. These observations suggest that interfering with the ability of bacteria to collaborate via QS can serve as a strategy to counteract microbial efforts to manipulate host defenses.

Importance: Streptococcus pyogenes is restricted to human hosts and commonly causes superficial diseases such as pharyngitis; it can also cause severe and deadly 
manifestations including necrotizing skin disease or severe post-infectious sequelae like rheumatic heart disease. Understanding the complex mechanisms used by this pathogen to manipulate host defenses could aid in developing new therapeutics to treat infections. Here, we examine the impact of a bacterial cell-cell communication system, which is highly conserved across $S$. pyogenes, on host innate immune responses. We find that $S$. pyogenes uses this system to suppress macrophage pro-inflammatory cytokine responses. Interference with this communication system could serve as a strategy to disarm bacteria and maintain an effective immune response. 


\section{Introduction}

Bacteria possess eloquent mechanisms to subvert host recognition and overcome the multiple barriers of human immune defenses. Strategies for survival have evolved to incorporate complex signaling systems that regulate genetic programs necessary to adapt to multiple environments and threats encountered in the host. Cellcell communication systems, such as quorum sensing (QS), allow bacteria to disseminate information about their environment, density, and metabolism through the transmission of extracellular signals. QS systems invoke social pressures that result in the synchronization of genetic programs across the population. This synchronization enables bacteria to function as a multicellular group better equipped to perform activities such as forming biofilms, producing virulence factors, or taking up foreign DNA. ${ }^{1}$

The bacterium Streptococcus pyogenes (Group A Strep, GAS) is a serious pathogen responsible for a high global burden of disease, including 616 million annual cases of GAS pharyngitis and 1.78 million annual cases of severe diseases like necrotizing fasciitis, toxic shock syndrome, rheumatic heart disease, and glomerulonephritis. ${ }^{2}$ GAS utilizes several QS systems, including RopB (Rgg1), Rgg2/3, ComR (Rgg4), and Sil. These systems have been shown to regulate virulence factors, biofilm production, competence genes, and invasive disease, respectively. ${ }^{1}$ Notably, the Rgg2/3 system is conserved across all serotypes of GAS, indicating its importance for GAS survival and making it an attractive system to study.

The transcriptional regulators Rgg2 and Rgg3 respond to two functionally equivalent short hydrophobic peptide ligands (SHP2 and SHP3, collectively referred to as SHP) in a concentration dependent manner. When concentrations of SHP are low, 
the repressive activity of Rgg3 predominates at target promoters. When SHP reaches a critical concentration ( $\sim \mathrm{nM}$ in culture conditions), it binds to Rgg2 and Rgg3 causing inactivation of Rgg3 (leading to de-repression of target genes) and activation of Rgg2 (leading to transcriptional activation of target genes). Genetic tools have helped identify two genetic loci that are directly controlled by the Rgg2/3 system: (1) the region adjacent to and including shp2, including spy49_0414c (stcA) and (2) the region adjacent to and including shp3 and spy49_0450-0460. Rgg2/3-mediated regulation of stcA promotes aggregation and biofilm development (two phenotypes that require adhesive surface structures) and resistance to lysozyme (an antimicrobial host factor that targets components of the bacterial cell wall). ${ }^{3,4}$ Because the surface of GAS interfaces with host cells, we hypothesized that Rgg2/3-mediated alterations to GAS would result in altered host immune responses.

Early innate immune responses to GAS are critical for control of infection. ${ }^{5}$ Pharmacological and genetic depletion studies established the importance of macrophages, dendritic cells (DCs), and neutrophils in initiating the innate immune response against GAS via distinct pathways. ${ }^{5-8}$ Macrophages are particularly important, as in vivo depletion or blockage of phagocytosis both drastically enhance susceptibility of mice to GAS. ${ }^{5,6}$ In response to GAS, macrophages upregulate expression of genes involved in inflammation, survival, and production of oxygen radicals, which help them eliminate GAS efficiently. ${ }^{9}$ Signaling through MyD88 in macrophages and dendritic cells is required for cytokine responses and GAS clearance, illustrating the importance of pathogen sensing through TLRs and IL1R in response to infection. ${ }^{10-13}$ Downstream of MyD88, a cascade of events leads to the translocation of NF $\kappa B$ family proteins to the 
nucleus, where they regulate expression of genes required to promote inflammation, including cytokines, adhesion molecules, and cell growth or death factors.

Because the Rgg2/3 QS system alters surface properties of GAS, this study aimed to determine the consequence on immune responses. Macrophages were infected with isogenic GAS mutants lacking either the transcriptional repressor, rgg3 (QS-locked ON) or the transcriptional activator, rgg2 (QS-locked OFF). Here, we report that Rgg2/3 activation limits pro-inflammatory cytokine responses to GAS. Moreover, QS activation resulted in suppression of cytokine responses induced by several TLR agonists. Expression of the putative biosynthetic gene cluster (BGC) downstream of shp3 was found to be required for this phenotype. Overall this study has identified a new role for Rgg2/3 QS in manipulating innate immune responses to GAS. 


\section{Results}

Macrophage responses to GAS are attenuated when Rgg2/3 QS is active.

Macrophages respond to GAS in part by activating $N F \kappa B$, a transcription factor capable of regulating expression of many pro-inflammatory cytokines. To determine if the GAS QS state impacts macrophage responses, pro-inflammatory responses were measured following in vitro infections with wild-type (WT), $\operatorname{rgg} 3$ (QS locked ON), or $\Delta$ rgg2 (QS locked OFF) GAS. Infection with WT or $\Delta r g g 2$ resulted in activation of NFאB and production of high amounts of TNF $\alpha$ and IL-6 (Fig 1A-B). Interestingly, infection with $\Delta r g g 3$ led to approximately 4-fold decreased NFאB reporter activity and 20-fold decreased TNF $\alpha$ and 25-fold decreased IL-6 production compared to infection with WT or $\operatorname{sgg} 2$ (Fig 1A-B). To determine if decreased activity was due to differences in macrophage cytotoxicity, extracellular release of the cytoplasmic enzyme lactate dehydrogenase (LDH) was measured as an indicator of plasma membrane damage. LDH release was minimal in response to WT and mutant GAS strains after 8 hours of infection (Fig 1C). Additionally, infecting macrophages with increasing $\mathrm{MOI}$ of $\Delta r g g 2$ resulted in dose-dependent activation of NFKB (Fig 1D). Increasing the MOI of $\Delta r g g 3$, however, failed to increase NFKB responses, and instead they remained attenuated even at the highest $\mathrm{MOI}$ tested.

The chemically defined medium (CDM) used to grow the bacteria in the laboratory lacks SHP pheromones and other signals capable of activating Rgg2/3 QS; thus the wild-type strain is QS-OFF when cultured in this medium. ${ }^{3,14}$ We have 
previously shown that exogenous addition of synthetic SHP pheromone during growth of WT culture activates Rgg2/3 QS within minutes. ${ }^{3}$ Macrophage inoculation with SHPactivated WT GAS (strain NZ131) led to attenuated TNF $\alpha$ production similarly to that of the genetically QS locked ON mutant, $\Delta r g g 3$ (Fig 1E). Macrophage responses WT GAS grown in the presence of the inactive reverse sequence of SHP (revSHP) mimicked that of the genetically QS locked OFF mutant, $\Delta$ rgg2.

Rgg2/3 QS is conserved across all sequenced serotypes of GAS. GAS serotypes are classified based on differences in M protein, a surface protein and major virulence factor. The strain NZ131 (serotype M49) was used for a majority of this work because it is a highly transformable strain and excellent tool for genetic manipulation of GAS. To confirm that the immunomodulatory phenotype is not restricted to NZ131, macrophage TNF $\alpha$ responses were measured following infection with other wild-type strains: HSC5 (M14), 5448 (M1), and MGAS315 (M3). These particular strains were chosen as representatives of diverse M types. Furthermore, we previously confirmed that Rgg2/3 activation leads to cell surface changes (lysozyme resistance and biofilm formation) in both HSC5 and MGAS315. ${ }^{14}$ Strain 5448 was added as a representative M1T1 globally disseminated, clinically relevant strain. With the exception of MGAS315, activation of Rgg2/3 QS by the addition of exogenous SHP resulted in reduced macrophage TNF $\alpha$ production in response to all other strains tested (Fig 1E). Curiously, minimal TNF $\alpha$ was produced in response to MGAS315, even without the activation of QS. This may be due to the strain's high expression of capsule, a virulence factor that prevents adherence and phagocytosis. ${ }^{15}$ 
To determine if the differential cytokine response is restricted to RAW264.7 macrophages, the effect of QS activation on cytokine production was also examined following in vitro infection of primary mouse bone marrow-derived macrophages (BMDM) and dendritic cells (BMDC). TNF $\alpha$ production by BMDM and BMDC was attenuated in response to $\Delta r g g 3$, consistent with responses seen in RAW264.7 cells (Fig 1F). These data suggest that $\Delta r g g 3$ is able to manipulate cytokine production in multiple innate immune cell types, indicating the potential relevance and applicability of interfering with QS as therapeutic strategy.

QS-ON GAS actively suppresses macrophage inflammatory responses.

To determine if QS enabled GAS to evade detection (i.e. hide) or rather to actively downregulate (i.e. suppress) inflammatory responses, macrophages were infected with mixed populations of $\Delta r g g 3$ and $\Delta r g g 2$, and $\mathrm{NF \kappa B}$ activity or cytokine production was measured. Following mixed infection with both $\Delta r g g 3$ and $\Delta r g g 2, N F \kappa B$ activity remained low and was similar to that of $\Delta r g g 3$ single infection (Fig 2A). Decreasing the $\mathrm{MOI}$ of $\Delta \mathrm{rgg} 3$ in mixed infections led to a dose-dependent increase in production of all cytokines tested (TNF $\alpha$, IL-6, IFN $\beta$ ). Surprisingly, cytokine production remained attenuated even when $\Delta r g g 3$ was outnumbered 5 to 1 by $\operatorname{\Delta rgg} 2$ (Fig 2B). TNF $\alpha$ production by primary mouse BMDM and BMDC was also attenuated following mixed infections with equal $\mathrm{MOI}$ of $\Delta r g g 2$ and either $\Delta r g g 3$ or WT grown in the presence of SHP (Fig 2C). Together these data suggest that QS enables GAS to suppress macrophage cytokine responses. 
The specific pathogen-associated molecular patterns (PAMPs) responsible for inducing pro-inflammatory responses to GAS are incompletely described; however, it has been well established that both the MyD88-NFKB pathway and the type I IFN pathway are required for clearance. ${ }^{11,13}$ We wondered whether QS would enable GAS to suppress stimulation by TLR agonists. TLR agonist-stimulated macrophages produced significantly higher amounts of TNF $\alpha$ when applied simultaneously with $\Delta r g g 2$ (Fig 2D). However, agonist treatment together with $\Delta r g g 3$ infection resulted in decreased TNF $\alpha$ production in response to lipopolysaccharide (LPS; TLR4), heat-killed $L$. monocytogenes (HKLM; TLR2), and CpG oligodeoxynucleotide (ODN1826; TLR9). Together, these data suggest that GAS suppresses NFאB-mediated pro-inflammatory responses downstream of TLR stimulation.

Suppression requires contact with live QS-ON GAS.

To localize the factor(s) responsible for QS-regulated cytokine modulation, the ability of secreted/extracellular components and surface-associated components to alter NFKB activity was tested. In other pathogenic bacteria, QS molecules themselves have been shown to possess immunomodulatory properties toward host cells. For example, treatment of epithelial cells with QS molecules produced by Pseudomonas aeruginosa (i.e. homoserine lactones, quinolones, and phenazines) results in differential regulation of cytokine expression via sensing by the host receptor AhR. ${ }^{16}$ Macrophage treatment with the Rgg2/3 QS molecule SHP failed to increase NFאB activity compared to untreated controls. Therefore, we tested whether addition of SHP to $\Delta$ rgg2 infected 
macrophages was sufficient to attenuate NFאB activity. We saw that addition of $200 \mathrm{nM}$ of either SHP or revSHP to macrophages was unable to suppress NFкB activity (Fig 3A). These data suggest that although SHP signals induce Rgg2/3 signaling, they are not directly responsible for the observed immunomodulatory effect.

To determine whether other secreted factors could enable QS-ON GAS to suppress NFKB activity, macrophages were directly stimulated with $\Delta r g g 2$ GAS, and $\Delta$ rgg3 GAS was added to macrophages either directly or separated by a $0.4 \mu \mathrm{m}$ pore trans-well membrane (TW). This size pore prohibited $\Delta$ rgg3 GAS from directly contacting macrophages, and it simultaneously allowed secreted factors to pass through the membrane. We determined that when $\Delta$ rgg3 GAS was added above the TW ( $\Delta r g g 3-T W)$, it was unable to suppress NFאB activity (Fig 3B, white bar). This indicated that macrophage suppression is a contact-dependent phenomenon. Furthermore, sterile filtered supernatants from $\Delta r g g 3$ cultures were added to macrophages infected with $\Delta r g g 2$ and failed to suppress NFผB activity, further indicating that GAS culture supernatants lack the factor responsible for suppressing macrophage responses (Fig 3C).

Our previous work illustrated that cell surface properties of GAS are altered via Rgg2/3 QS. ${ }^{3,4,14}$ To examine if these surface changes include alterations of the repertoire or display of antigens, macrophages were infected with GAS inactivated by different methods, including heat (heat killed, HK), short wave ultraviolet light (UV), and 4\% paraformaldehyde (PFA) treatment. While heat has been shown to alter cell wall peptidoglycans and denature proteins, UV treatment damages DNA and RNA and is less likely to interfere with cell surface properties. PFA treatment crosslinks amines in 
proteins and other structures within the cell. We posited that if QS-induced surface changes are responsible for altered macrophage responses, infection with inactivated GAS would similarly result in differential inflammatory responses. After each inactivation treatment, bacteria were plated for enumeration to confirm loss of viability, and in each case $>99.9 \%$ of cells were non-recoverable. Macrophages infected with inactivated GAS had lower NF↔B activity compared to those infected with live GAS, and this was consistent across all treatments (Fig $3 \mathbf{C}$ ). Inactivation of GAS with heat and UV eliminated the QS-dependent differences in NFKB activity (Fig 3C). Furthermore,

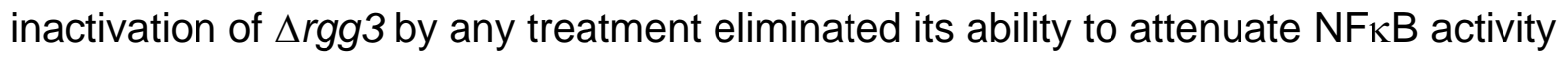
when added to cells stimulated with live, metabolically active $\Delta r g g 2$ (Fig $3 \mathbf{C}$ ). This suggests that alterations in surface properties are unlikely responsible for the differences in macrophage responses to $\Delta r g g 3$ GAS, though it is possible that these inactivation methods may have interfered with the unknown ligand responsible for immunosuppression. Cumulatively, these data indicate that immunomodulation by QSON GAS requires live bacteria and direct contact between the pathogen and host cells.

\section{Suppression does not require bacterial internalization}

GAS initially interacts with macrophages through bacterial adherence and internalization. Though GAS was first thought to be an exclusively extracellular pathogen, much evidence has illustrated that it can also invade and even replicate intracellularly. ${ }^{17,18}$ While it appears that contact is required for QS-mediated immunosuppression (Fig 3B), we next wondered whether GAS must also be 
internalized to suppress macrophage responses. Inhibition of macrophage actin polymerization by treatment with Cytochalasin $D(C y t D)$ is well described to prevent phagocytosis of bacteria, including S. pyogenes.$^{19}$ To determine whether QS-mediated suppression requires internalization of GAS, macrophages were pre-treated with CytD and then infected with $\Delta r g g 3$. After killing extracellular GAS with gentamicin for 30 minutes and washing away any remaining GAS, antibiotic, and CytD, LPS or $\Delta$ rgg2 was added to stimulate the cells. We showed that inhibiting phagocytosis had no effect on the ability of QS-ON GAS to suppress stimulation by LPS or $\Delta$ rgg2 GAS (Fig 4A). Next, to determine if QS activity modulates the degree to which GAS adheres to macrophages, GAS was plated for CFU enumeration after infection and compared to the initial inoculum. As a negative control, the $\Delta \operatorname{cov} R$ mutant strain of GAS was also tested because this strain is well defined to overexpress capsule (an antiphagocytic and anti-adherence factor). Adherence to macrophages after 30 minutes of infection was not affected by the QS-state of GAS (Fig 4B).

A QS-regulated operon is required for cytokine suppression

Several virulence factors have been described as important in manipulating immune responses to GAS, including streptolysin O (SLO), S. pyogenes cell envelope protease (SpyCEP), M protein, and capsule, all of which interact with the bacterial surface. ${ }^{20,21}$ To test whether any of these are involved, we activated the Rgg2/3 system by addition of SHP pheromone in isogenic strains lacking SLO $(\Delta s / 0)$, capsule ( $\triangle$ has $A B)$, M protein $(\Delta e m m)$, or SpyCEP $(\Delta s p y c e p)$. When QS was activated, each of these strains 
maintained their capacity to suppress macrophage NF↔B upon infection suggesting that these factors are not involved in the QS-dependent phenotype (Fig 5A).

The major genetic targets of the Rgg2/3 QS pathway include: (1) spy49_0414c, encoding the protein StcA and (2) spy49_0450-0460, encoding a putative biosynthetic gene cluster (BGC) (Fig 5B). ${ }^{3}$ We previously described that activation of Rgg2/3 QS mediates production of biofilms and resistance to the host antimicrobial factor lysozyme, two phenotypes that rely on surface modifications and were shown to require QSregulation of StcA. ${ }^{3,4}$ We wondered whether regulation of StcA also enabled suppression of inflammatory pathways in innate immune cells. Infecting macrophages with $\Delta 0414 c$ and $\Delta 0450-0460$ grown in the presence of SHP (QS-ON) or inactive revSHP (QS-OFF) showed that while spy49_0414c is not required for QS-regulated attenuation of cytokine responses, spy49_0450-0460 is required (Fig 5C). Further interrogation using isogenic mutants of various genes within this pathway determined that QS-ON GAS lacking either the first six genes (spy49_0450-0456) or the second to last gene, spy49_0459, failed to attenuate NFKB activity following single infections (Fig 5C). Interestingly, infection with QS-ON GAS lacking only spy49_0460 attenuated NFאB activity to similar levels as infection with the WT control (Fig 5C). Consistent with this observation, mixed infections with QS-OFF GAS and WT or BGC mutants grown in the presence of SHP pheromone (QS-ON), demonstrated that BGC mutants significantly restored the NFKB response, suggesting these genes are involved in suppression (Fig 5D). A mutant strain lacking only spy49_0460, however, retained its ability to suppress NFkB activity, again suggesting this gene is not required for this activity. Complementation of spy49_0450-0457 or spy49_0459 in the corresponding deletion 
strains was able to restore suppression capability (Fig 5E-F). However, complementation of spy49_0450-0457 in $\Delta$ 0450-0460 failed to fully complement suppression, suggesting the importance of later genes in the BGC, such as spy49_0459 (Fig 5F). Together, these data suggest that the previously described surface alterations mediated by stcA are not responsible for macrophage suppression by QS-ON GAS, and instead genes in the BGC are involved.

Rgg2/3 QS can be targeted pharmacologically to restore immunity

The ability of QS-activated GAS to suppress host cytokine responses could be a new potential mechanism to target in vivo as an anti-virulence treatment strategy. Previous screening of a library of FDA approved drugs identified cyclosporine-A (CsA) as an inhibitor of Rgg2/3 QS signaling. The CsA analog valspodar, which lacks immunosuppressive effects, was also found to inhibit signaling. ${ }^{22}$ To determine if pharmacologically inhibiting QS could prevent immunosuppression, $\Delta r g g 3$ and $\Delta r g g 2$ cultures were treated with $10 \mu \mathrm{M}$ valspodar and then applied to macrophages.

Compared with untreated $\Delta r g g 3$, valspodar-treated GAS was no longer able to suppress cytokine production in macrophages. These data indicate that blocking QS-signaling can restore macrophage responses to GAS and eliminate their ability to suppress cytokine production. 


\section{Discussion}

This study presents a novel phenomenon whereby GAS utilizes an intercellular regulatory system to actively suppress NFKB activity and pro-inflammatory cytokine production in macrophages and dendritic cells. Bacteria incapable of responding to pheromone signals (QS-OFF mutants) lacked the ability to suppress immune cell responses. QS-ON GAS that were inactivated by heat treatment, fixation, or UV irradiation also lost their ability to suppress inflammatory responses. This indicates that suppression is an active process occurring at the interface of GAS and macrophages rather than presentation of a stable surface moiety by GAS. Cell-free culture supernatants also failed to suppress inflammatory responses, further supporting the notion that a secreted factor is not released into the surrounding milieu. Separation of bacteria from stimulated macrophages by a trans-well membrane also abolished suppression capacity of QS-ON GAS. Together, these data support a model whereby GAS contacts innate immune cells and, when QS signaling is active, presents or delivers a factor that interrupts host signaling pathways.

The Rgg2/3 QS system directly regulates two operons, each encoding a shp gene and additional coding sequences: spy49_0414c(stcA) and spy49_0450-0460, a putative biosynthetic gene cluster. Here, we were able to link immune cell suppression activity to expression of spy49_0450-0460; deletion of the operon abolished suppression. This locus is conserved across all sequenced GAS genomes and is comprised of 10 genes co-expressed from the shp3 promoter. They encode various enzymes involved in amino acid biosynthesis, sugar metabolism, and cell wall biogenesis (Fig 5B). The operon was found to be repressed by the metal dependent 
regulator MtsR, and some of the genes were identified in screens for those involved in invasive infection and survival in blood. ${ }^{23-25}$ Yet, little remains known about this putative biosynthetic gene cluster, and similar gene sets are seen in only a few other instances in S. porcinus, S. pseudoporcinus, Salinispora tropica, and Bacillus thuringiensis. Curiously, in $B$ thuringiensis, the homologous gene cluster is implicated in the biosynthesis of a secreted toxin called thuringensin, a nucleoside analog predicted to have cytotoxic activity. ${ }^{26}$ We observed no cytotoxic impact to macrophages incubated with QS-ON or QS-OFF cells (Fig 1C); however, we hypothesize that the product of the spy49_0450-0460 gene cluster could be a bioactive molecule produced in response to and directed at macrophages. The last gene of the operon, spy49_0460 (mefE), encodes a putative efflux protein. The presence of this gene in the operon is consistent with the notion that it aids in delivery of a molecule. Surprisingly, however, deletion of mefE did not affect QS-mediated cytokine suppression in macrophages, refuting its potential involvement in the observed activity, unless a redundant pathway is capable of releasing a factor.

Bacteria use diverse strategies to modulate host responses. We hypothesize that GAS produces a QS-regulated factor that can manipulate host signaling pathways and subsequently shape cytokine responses. Upon TLR activation, a cascade of phosphorylation and ubiquitination events leads to degradation of the inhibitor $I_{\kappa} B$, allowing $\mathrm{NF}_{\kappa} \mathrm{B}$ translocation to the nucleus where it regulates transcription. Here, we demonstrate that GAS suppresses stimulation at a step downstream of TLR activation

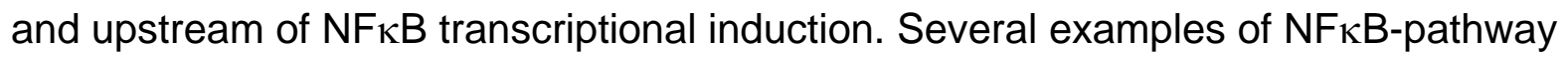
disruptors have been described in Gram-negative pathogens, and include Yersinia 
YopJ, E. coli Nle proteins, and Shigella Osp proteins. ${ }^{27}$ Fewer examples have been described in Gram-positive pathogens which largely lack specialized secretion systems used to deliver factors directly to host cells. We found that QS-induced suppression of macrophages required contact with live GAS and was not found in supernatants, (Fig 3) This suggests the factor is not released from bacteria into extracellular spaces, but instead it might be delivered by a mechanism allowing translocation across the host membrane, such as that seen in Type III secretion systems (T3SS). In GAS, delivery of the virulence factor NAD-glycohydrolase (NADase) has been shown to occur in a mechanism functionally equivalent to T3SS, but requiring the pore-forming toxin, streptolysin O (SLO) for delivery. ${ }^{28,29}$ We induced the Rgg2/3 system in a strain lacking SLO $(\Delta s / 0)$ and found it maintained its capacity to suppress NFkB (Fig $5 \mathrm{~A})$. Thus, if Rgg2/3-dependent immune suppression involves a translocated factor, effector delivery may involve as-of-yet characterized delivery mechanisms.

The ability of Staphylococcus aureus, another Gram-positive pathogen, to actively interfere with host signaling components does not necessitate translocation of factors into host cells. For example, staphylococcal superantigen-like protein (SSL3) binds TLR2 and blocks ligand binding and TLR heterodimerization, thereby inhibiting macrophage stimulation. ${ }^{30,31}$ Another protein, TirS, blocks TLR-dependent NFKB activation by mimicking and interfering with host TIR-containing adaptor proteins (like MyD88), and presumably must enter the host cell cytoplasm in order to function. ${ }^{32}$ How TirS gains access to the host cytosol is unresolved.

Although many GAS virulence factors facilitate immune evasion by various mechanisms, none have been described to suppress NFKB responses. Multiple 
virulence factors in GAS can suppress cytokines post-translationally. For example, SLO induces host degradation of IL-1 $\beta$ via ubiquitination, and SpyCEP directly degrades IL-8 via proteolytic cleavage. ${ }^{33,34}$ Here, we describe a distinct mechanism of suppression upstream of these pathways. Interestingly, the strain MGAS315 was the only strain tested which failed to suppress macrophage cytokine responses (Fig 1E). Further exploration of the differences between the MGAS315 strain and the others could help shed light on the bacterial factors responsible for the differences in macrophage responses. We suspect that differences in capsule, which prevents adherence to host cells, are involved because direct contact was required for suppression (Fig 3). We plan to examine this by deleting capsule genes in this strain and assessing its immunomodulatory potential. Interestingly, deleting capsule genes in NZ131 did not improve suppression compared to WT, suggesting there may be redundant factors involved.

Rgg2/3 QS is activated in response to environmental conditions found in host mucosal environments, including metal depletion and mannose utilization. ${ }^{14}$ It remains unclear what benefits are afforded by the additional layer of intercellular communication signaling. We recently demonstrated the importance of Rgg2/3 QS activation in vivo for nasopharyngeal colonization. ${ }^{35}$ Whether Rgg2/3-mediated immunosuppression was a contributing factor in the observed increased colonization rates of rgg3 mutants (QSON) was not a component of these studies, but blocking NF $\kappa B$ signaling likely diminishes the efficacy of host strategies for bacteria eradication, including production of antimicrobial factors (lysozyme, cationic peptides), induction of autophagic responses, and recruitment of additional phagocytic and cytotoxic immune cells. Incorporating cell- 
cell signaling under threatening conditions likely reinforces bacterial compliance to engage defense mechanisms that improve probabilities of survival if immune responses are blunted.

As we gain deeper understanding of how QS systems are used by bacteria to enhance fitness attributes in the context of host colonization and/or infection, the more promising it becomes to target signaling activities pharmacologically as an alternative or supplementary therapeutic approach to antibiotics. We previously determined that the FDA-approved drugs cyclosporin A and valspodar have specific inhibitory activities against Rgg2/3 QS. ${ }^{22}$ We are encouraged by results shown here that blocking QSactivity with valspodar abolished its cytokine attenuation effects and restored macrophage inflammatory responses to GAS in vitro. Testing methodologies that incorporate anti-QS therapeutics remains a compelling strategy that could bolster the host's intended immune response and diminish infections by this global pathogen. 


\section{Acknowledgments}

We thank Drs. Reid Wilkening and Juan Jimenez for strain construction, Dr. Benjamin Gantner for RAW264.7 cells, and Drs. Donna Macduff, Francis Alonzo, and David Ucker for helpful discussions. This study was supported by NIH R01Al091779 to M.J.F. and NIH F31Al147429 to K.R.

\section{Author Contributions}

Conceptualization, data analysis, and funding acquisition, K.R. and M.J.F.;

Investigation, K.R. and J.C.; Writing, K.R.; Reviewing and editing, M.J.F., K.R., and J.C.

\section{Declaration of Interests}

The authors declare no competing interests. 


\section{Figure Titles and Legends}

\section{Figure 1. Macrophage responses to GAS are attenuated when Rgg2/3 QS is} active.

(A) NFkB responses after infecting RAW246.7 cells containing a chromosomally integrated NFאB-inducible secreted embryonic alkaline phosphatase reporter (RAWBlue cells) with wild-type (WT) $\Delta r g g 2$ (QS-OFF), or $\Delta r g g 3$ (QS-ON) GAS. All cells were infected with MOI 10 unless otherwise indicated. Reporter activity (absorbance $625 \mathrm{~nm}$ ) is shown.

(B) TNFa and IL-6 production by RAW264.7 cells 8 hours after infection.

(C) LDH release as a measurement of macrophage cell death 8 hours after infection.

Percentage of dead cells was quantified using a $100 \%$ lysed cell control.

(D) NFאB activity after infecting RAW-Blue cells for 20 hours with different multiplicities of infection (MOI) of $\Delta r g g 2$ (black bars) or $\Delta r g g 3$ (blue bars).

(E) TNF $\alpha$ production by RAW264.7 cells 8 hours after infection with different serotypes of GAS grown in the presence of revSHP (black bars) or SHP (blue bars).

(F) TNF $\alpha$ production by BMDM or BMDC 8 hours after infection with GAS (strain NZ131) grown in the presence of revSHP (black bars) or SHP (blue bars). Means $\pm S D$ are shown from a representative of three independent experiments conducted in triplicate. ${ }^{* \star *} \mathrm{p}=0.001 ;{ }^{* * *} \mathrm{p}<0.0001$ by two-tailed unpaired $t$ test $(\mathrm{A}-\mathrm{B})$ or ordinary one-way ANOVA with Tukey's multiple comparisons test (C-E).

Figure 2. QS-ON GAS actively suppresses inflammatory responses. 
(A) NF/B activity after infecting RAW-Blue cells with $\Delta r g g 2, \Delta r g g 3$, or both.

(B) TNF $\alpha$, IL-6, and IFN $\beta$ production after RAW264.7 cells were infected with the described MOls of $\Delta r g g 2$ and $\Delta r g g 3$.

(C) TNF $\alpha$ production by BMDM or BMDC 8 hours after infection with MOI 10 of $\Delta$ rgg2 or co-infected with MOI 10 of each $\Delta r g g 2$ and $\Delta r g g 3$ or $\Delta r g g 2$ and WT grown in the presence of SHP.

(D) TNF $\alpha$ production after RAW264.7 cells were co-incubated with TLR agonists and $\operatorname{rgg} 3$ or $\Delta r g g 2$. LPS, lipopolysaccharide (TLR4); HKLM, Heat killed Listeria monocytogenes (TLR2); ODN1826, CpG oligodeoxynucleotide (TLR9).

Means $\pm S D$ are shown from a representative of two (D) or three $(A-C)$ independent experiments conducted in triplicate. ${ }^{*} p<0.05 ;{ }^{* *} p<0.005 ;{ }^{* *} p<0.001 ;{ }^{* * \star *} p<0.0001$, by ordinary one-way ANOVA with Tukey's multiple comparisons test (A-C) or two-way ANOVA with Sidak's multiple comparisons test (D).

Figure 3. Suppression requires contact with live QS-ON GAS.

(A) NFKB activity after stimulating RAW-Blue cells with MOI $10 \Delta r g g 2$ and treating with 200 nM SHP or revSHP, or MOI 10 srgg3.

(B) NFKB activity after infecting RAW-Blue cells directly with the described strains, or with $\Delta r g g 3$ separated by a trans-well with 0.4 um pores (TW).

(C) NFкB activity after infecting RAW-Blue cells with live $\Delta r g g 2$ and/or GAS that was inactivated with heat treatment (HK), short wave ultraviolet light treatment (UV), or $4 \%$ paraformaldehyde (PFA), or OD-normalized sterile filtered supernatants (supe). 
Means $\pm S D$ are shown from a representative of three independent experiments conducted in triplicate. ${ }^{* * * *} p<0.0001$ by two-way ANOVA with Sidak's multiple comparisons test $(A-B)$ or ${ }^{* * * *} p<0.0001$, by ordinary one-way ANOVA with Tukey's multiple comparisons test (C-D).

Figure 4. Suppression does not require bacterial internalization

(A) TNF $\alpha$ production (Left graph) or NFאB activity (Right graph) after RAW264.7 cells were pre-treated with Cytochalasin D and infected with $\Delta r g g 3$ for 30 minutes, followed by stimulation with LPS or $\Delta r g g 2$.

(B) GAS adherence to RAW264.7 cells after 30 minutes of infection. Adherence was calculated as the percentage of viable bacterial cells recovered compared to infection inoculum.

Means \pm SD are shown from a representative of two independent experiments conducted in triplicate. ${ }^{* * *} \mathrm{p}=0.002,{ }^{* * * *} \mathrm{p}<0.0001$, by two-way ANOVA with Sidak's multiple comparisons-test (A) and ordinary one-way ANOVA with Tukey's multiple comparisons test (B).

Figure 5. A QS-regulated biosynthetic gene cluster (BGC) is required for cytokine suppression

(A) NFKB activity of RAW-Blue cells infected with MOI 10 of GAS isogenic mutants lacking various virulence factor genes and grown in the presence of SHP. Following 30 minutes of infection, macrophages were stimulated with LPS. 
(B) Diagram depicting the QS-regulated genetic programs in GAS (strain NZ131), putative functions of the genes, and the isogenic mutants used in subsequent assays.

(C) NFKB activity after RAW-Blue cells were infected with MOI 10 of the described GAS genetic mutant strains grown in the presence of either inactive reverse SHP (revSHP) or active SHP.

(D) NFkB activity after RAW-Blue cells were co-infected with MOI 10 srgg2 and $\mathrm{MOI} 10$ of the described BGC mutants grown in the presence of SHP.

(E-F) NFKB activity after RAW-Blue cells were stimulated with MOI $10 \Delta r g g 2$ (E) or 100ng/ml LPS (F) and infected with BGC mutants and complementation strains. All GAS strains were grown in the presence of SHP to induce Rgg2/3 QS activity. Means $\pm S D$ are shown from a representative of three independent experiments conducted in triplicate. ${ }^{* * *} \mathrm{p}<0.0001$, by ordinary one-way ANOVA with Tukey's multiple comparisons test (A, D-F) or two-way ANOVA with Sidak's multiple comparisons-test (C).

\section{Figure 6. Rgg2/3 QS can be targeted pharmacologically to restore immunity.}

TNF $\alpha$ production after RAW264.7 cells were infected with GAS that was treated with or without the QS inhibitor valspodar $(10 \mu \mathrm{M})$. Means \pm SD are shown from a representative of three independent experiments conducted in triplicate. ${ }^{* * *} \mathrm{p}<0.0001$, by two-way ANOVA with Tukey's multiple comparisons-test. 


\section{Tables}

\begin{tabular}{|c|c|c|}
\hline Strain & Description & Reference \\
\hline$\Delta \operatorname{cov} R$ & NZ131 $\Delta \operatorname{cov} R ;$, unmarked & \\
\hline 5448 & Wild-type M1 isolate of the M1T1 lineage & 31 \\
\hline HSC5 & Wild-type M14 isolate & 38,39 \\
\hline JCC131 & $\mathrm{NZ131}$ argg3:: cat; $\mathrm{cm}^{\mathrm{R}}$ & 3 \\
\hline JCC137 & NZ131 vrgg2; unmarked & 3 \\
\hline JCC155 & NZ131 sspy49_0450-0456; unmarked & This study \\
\hline JCC173 & $\mathrm{NZ131} \Delta$ spyCEP::aphA3; $\mathrm{kan}^{\mathrm{R}}$ & This study \\
\hline JCC303 & NZ131 sspy49_0450-0460; unmarked & This study \\
\hline JCC304 & NZ131 $\Delta$ spy49 0459; unmarked & This study \\
\hline JCC306 & NZ131 Aspy49_0460; unmarked & This study \\
\hline JCJ134 & $\mathrm{NZ131} \Delta$ hasAB::cat; $\mathrm{cm}^{\mathrm{R}}$ & This study \\
\hline JCJ173 & NZ131 $\Delta s t c A ;$ unmarked & \\
\hline MGAS315 & Wild-type M3 isolate & 40,41 \\
\hline NZ131 & Wild-type M49 isolate & 42 \\
\hline RVW113 & $\mathrm{NZ131} \Delta e m m:: a p h A 3 ; \operatorname{kan}^{\mathrm{R}}$ & This study \\
\hline RVW179 & NZ131 $\Delta s / 0_{1-260}:: a p h A 3 ; \operatorname{kan}^{\mathrm{R}}$ & This study \\
\hline Plasmid & Description & Reference \\
\hline p7INT & $\begin{array}{l}\text { Shuttle-suicide vector that integrates at a } \\
\text { streptococcal prophage tmRNA site; for } \\
\text { complementation in single copy; erm }\end{array}$ & \\
\hline pFED760 & $\begin{array}{l}\text { Shuttle vector pGh9-ISS1 deleted for ISS1 element; } \\
\text { used for constructing all deletion mutants; } \\
\text { temperature-sensitive replication origin; } \text { erm }^{R}\end{array}$ & 45 \\
\hline pJC202 & $\begin{array}{l}\text { To construct unmarked deletion of spy49_0450-0456; } \\
\text { in pFED760; erm }\end{array}$ & This study \\
\hline pJC233 & $\begin{array}{l}\text { Complementation of spy49_0450-0457 in multi-copy; } \\
\text { in pLZ12-Sp; sp }{ }^{R} \text {. Nicknamed p0450-57 in text. }\end{array}$ & This study \\
\hline pJC258 & $\begin{array}{l}\text { To replace spyCEP with the aphA3 kanamycin } \\
\text { resistance marker; in pFED760; } \operatorname{kan}^{\mathrm{R}} \mathrm{erm}^{\mathrm{R}}\end{array}$ & 36 \\
\hline pJC411 & $\begin{array}{l}\text { To construct unmarked deletion of spy49_0450-0460; } \\
\text { in pFED760; erm }\end{array}$ & This study \\
\hline pJC412 & $\begin{array}{l}\text { To construct unmarked deletion of spy49_0459; in } \\
\text { pFED760; erm }{ }^{\mathrm{R}}\end{array}$ & This study \\
\hline pJC414 & $\begin{array}{l}\text { To construct unmarked deletion of spy49_0460; in } \\
\text { pFED760; erm }\end{array}$ & This study \\
\hline pJC420 & 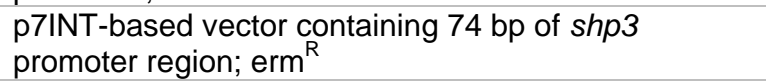 & This study \\
\hline pJC469 & $\begin{array}{l}\text { Complementation of spy } 49 \text {-0459 in single copy; in } \\
\text { pJC420; erm }{ }^{\mathrm{R}} \text {. Nicknamed } 0459 \text { in text. }\end{array}$ & This study \\
\hline pJJ148 & $\begin{array}{l}\text { To replace has } A B \text { with the cat chloramphenicol } \\
\text { resistance cassette; in pFED760; } \mathrm{cm}^{\mathrm{R}} \mathrm{erm}^{\mathrm{R}}\end{array}$ & This study \\
\hline pLZ12-Sp & Shuttle vector for complementation in multi-copy; $\mathrm{sp}^{\mathrm{H}}$ & 46 \\
\hline pRVW48 & $\begin{array}{l}\text { To replace the emm } 49 \text { region with aphA3 kanamycin } \\
\text { resistance marker; in pFED760; } \text { kan }^{\mathrm{R}} \mathrm{erm}^{\mathrm{R}}\end{array}$ & This study \\
\hline pRVW82 & $\begin{array}{l}\text { To replace the } \mathrm{N} \text {-terminal } 260 \text { amino acids of slo with } \\
\text { the aphA3 kanamycin resistance marker }\end{array}$ & This study \\
\hline
\end{tabular}

$\mathrm{cm}=$ chloramphenicol; erm = erythromycin; kan = kanamycin; $\mathrm{sp}=$ spectinomycin 
Table 2. Primers used in this study

\begin{tabular}{|c|c|c|c|}
\hline Purpose & Primer & Sequence & Description \\
\hline \multirow[t]{4}{*}{ pJC202 } & JC195 & CATGGCGGCCGCAGAAGCTCAAGAGATGACC & $\begin{array}{l}\text { S primer for upstream } \\
\text { flanking region; Notl }\end{array}$ \\
\hline & JC133 & GAATTCTACACAGAGCTAACCATTACC & $\begin{array}{l}\text { AS primer for upstream } \\
\text { flanking region }\end{array}$ \\
\hline & JC193 & CTCTGTGTAGAATTCAGATAGTGAAGGGTATTTTCG & $\begin{array}{l}\text { S primer for downstream } \\
\text { flanking region }\end{array}$ \\
\hline & JC194 & CATGGCGGCCGCCCAAACTGGCATCTAACC & $\begin{array}{l}\text { AS primer for downstream } \\
\text { flanking region; Notl }\end{array}$ \\
\hline \multirow[t]{2}{*}{ pJC233 } & JC288 & GCATGGGATCCATATTTTCCCACTTTCCC & $\begin{array}{l}\text { S primer for spy } 49 \_0450 \text {; } \\
\text { BamHI }\end{array}$ \\
\hline & JC290 & GCATGGGATCCCCAAACTGGCATCTAACC & $\begin{array}{l}\text { AS primer for } \\
\text { spy } 49 \text { 0 } 0457 \text {; BamHI }\end{array}$ \\
\hline \multirow[t]{4}{*}{ pJC411 } & JC575 & $\begin{array}{l}\text { GAGGATCCCACCGCGGTGGCGGCCGCCAAGAACTT } \\
\text { GTATGGCTTG }\end{array}$ & $\begin{array}{l}\text { S primer for upstream } \\
\text { flanking region }\end{array}$ \\
\hline & JC576 & $\begin{array}{l}\text { TATTCTAAATACTAACGCGTTACACAGAGCTAACCATT } \\
\text { ACC }\end{array}$ & $\begin{array}{l}\text { AS primer for upstream } \\
\text { flanking region }\end{array}$ \\
\hline & JC577 & $\begin{array}{l}\text { ACGCGTTAGTATTTAGAATATTATTTAAAAAGTATAAT } \\
\text { ATTC }\end{array}$ & $\begin{array}{l}\text { S primer for downstream } \\
\text { flanking region }\end{array}$ \\
\hline & JC578 & $\begin{array}{l}\text { GGATCCACTAGTTCTAGAGCGGCCGCAGAGAGTCAA } \\
\text { TTAACAACTCTAAAC }\end{array}$ & $\begin{array}{l}\text { AS primer for downstream } \\
\text { flanking region }\end{array}$ \\
\hline \multirow[t]{4}{*}{ pJC412 } & JC579 & $\begin{array}{l}\text { GAGGATCCCACCGCGGTGGCGGCCGCAAACTATTAA } \\
\text { TGATAATTCTTTGAATC }\end{array}$ & $\begin{array}{l}\text { S primer for upstream } \\
\text { flanking region }\end{array}$ \\
\hline & JC580 & $\begin{array}{l}\text { GTTTTTTGTTAACGCGTGTTAACCTCTATTCTAAAACTT } \\
\text { TTTATAAATC }\end{array}$ & $\begin{array}{l}\text { AS primer for upstream } \\
\text { flanking region }\end{array}$ \\
\hline & JC581 & AGAGGTTAACACGCGTTAACAAAAACATTTTTGCG & $\begin{array}{l}\text { S primer for downstream } \\
\text { flanking region }\end{array}$ \\
\hline & JC582 & $\begin{array}{l}\text { GGATCCACTAGTTCTAGAGCGGCCGCTATAAAATGG } \\
\text { GGGAGCTAAC }\end{array}$ & $\begin{array}{l}\text { AS primer for downstream } \\
\text { flanking region }\end{array}$ \\
\hline \multirow[t]{6}{*}{ pJC414 } & JC569 & $\begin{array}{l}\text { CTCTAGAGGATCCCACCGCGGTGGCGGCCGCAACTA } \\
\text { ACCTAAAAGTTAATAAGCTTG }\end{array}$ & $\begin{array}{l}\text { S primer for upstream } \\
\text { flanking region }\end{array}$ \\
\hline & JC585 & $\begin{array}{l}\text { TATTCTAAATACTAACGCGTTTTAAAGACCTTTAAAAT } \\
\text { TTTCAG }\end{array}$ & $\begin{array}{l}\text { AS primer for upstream } \\
\text { flanking region }\end{array}$ \\
\hline & JC577 & $\begin{array}{l}\text { ACGCGTTAGTATTTAGAATATTATTTAAAAAGTATAAT } \\
\text { ATTC }\end{array}$ & $\begin{array}{l}\text { S primer for downstream } \\
\text { flanking region }\end{array}$ \\
\hline & JC578 & $\begin{array}{l}\text { GGATCCACTAGTTCTAGAGCGGCCGCAGAGAGTCAA } \\
\text { TTAACAACTCTAAAC }\end{array}$ & $\begin{array}{l}\text { AS primer for downstream } \\
\text { flanking region }\end{array}$ \\
\hline & JJ13 & CATGAGATCTTGTCACCTAAATAGCTTGGC & $\begin{array}{l}\text { S primer for inverse PCR } \\
\text { on pJC420; Bglll }\end{array}$ \\
\hline & JC592 & CATGGCGGCCGCCTTCCTTTCAGTTTTTATTTAT & $\begin{array}{l}\text { AS primer for inverse } \\
\text { PCR on pJC420; Notl }\end{array}$ \\
\hline \multirow[t]{2}{*}{ pJC469 } & JC686 & CATGGCGGCCGCATGAAAATTACAGTTGTAGGC & $\begin{array}{l}\text { S primer for spy49_0459; } \\
\text { Notl }\end{array}$ \\
\hline & JC687 & CATGAGATCTTTCAGATATAATAACTTTTAACTG & $\begin{array}{l}\text { AS primer for } \\
\text { spy49_0459; Bglll }\end{array}$ \\
\hline \multirow[t]{6}{*}{ pJJ148 } & JC125 & CATGGTCGACGCGTTATTCAACAACATCG & $\begin{array}{l}\text { S primer for upstream } \\
\text { flanking region; Sall }\end{array}$ \\
\hline & JJ102 & CATGTTAATTAAGGGACAATTACACCTCTTTC & $\begin{array}{l}\text { AS primer for upstream } \\
\text { flanking region; } \mathrm{Pacl}\end{array}$ \\
\hline & JJ103 & CATGTTAATTAATAGCCATGTCTTCATCTATAACA & $\begin{array}{l}\text { S primer for downstream } \\
\text { flanking region; } \mathrm{Pacl}\end{array}$ \\
\hline & JC124 & CATGGCGGCCGCCTTTAAGAAGGGCTTGTAGG & $\begin{array}{l}\text { AS primer for downstream } \\
\text { flanking region; Notl }\end{array}$ \\
\hline & $\begin{array}{l}\text { cat-S2- } \\
\text { Pacl }\end{array}$ & GCGTGTTAATTAAGGTATCGATAAGCTTGATGAA & S primer for cat; Notl \\
\hline & $\begin{array}{l}\text { cat-A2- } \\
\text { Pacl }\end{array}$ & GCGTGTTAATTAAGAAAAAGGAGAAGTCG & AS primer for cat; Notl \\
\hline pRVW48 & RW143 & TGGATCCCCCGGGCTGCAGGAATTCTGAAATGTTTTC & S primer for upstream \\
\hline
\end{tabular}


bioRxiv preprint doi: https://doi.org/10.1101/2020.1203.411157: this version posted December 4, 2020. The copyright holder for this preprint (which was not certified by peer review) is the author/funder, who has granted bioRxiv a license to display the preprint in perpetuity. It is made available under aCC-BY-NC-ND 4.0 International license.

\begin{tabular}{|c|c|c|c|}
\hline & & TAACCACC & flanking region \\
\hline & RW144 & TCATTTTAGCCATTGTTTACTCCTTATTTCTTAACTTTC & $\begin{array}{l}\text { AS primer for upstream } \\
\text { flanking region }\end{array}$ \\
\hline & RW147 & ATTGTTTTAGGCCTTTAAAACTTGGTTTTTTGTAACG & $\begin{array}{l}\text { S primer for downstream } \\
\text { flanking region }\end{array}$ \\
\hline & RW148 & $\begin{array}{l}\text { TACCGGGCCCCCCCTCGAGGTCGACAGCCTCAGGCA } \\
\text { TCGCACC }\end{array}$ & $\begin{array}{l}\text { AS primer for downstream } \\
\text { flanking region }\end{array}$ \\
\hline & RW145 & GGAGTAAACAATGGCTAAAATGAGAATATCAC & S primer for aphA3 \\
\hline & RW146 & AAGTTTTAAAGGCCTAAAACAATTCATCCAGTAAA & AS primer for aphA3 \\
\hline pRVW82 & RVW183 & $\begin{array}{l}\text { TGGATCCCCCGGGCTGCAGGAATTCGTCAACGATTG } \\
\text { GTCGACAAG }\end{array}$ & $\begin{array}{l}\text { S primer for upstream } \\
\text { flanking region }\end{array}$ \\
\hline & RVW184 & $\begin{array}{l}\text { TCATTTTAGCCATGTCCTTCATACCTTTTTATCATTCTA } \\
\text { AAATG }\end{array}$ & $\begin{array}{l}\text { AS primer for upstream } \\
\text { flanking region }\end{array}$ \\
\hline & RVW274 & ATTGTTTTAGTCACAGATTGAAGCAGCTC & $\begin{array}{l}\text { S primer for downstream } \\
\text { flanking region }\end{array}$ \\
\hline & RVW275 & $\begin{array}{l}\text { TACCGGGCCCCCCCTCGAGGTCGACCTACTTATAAG } \\
\text { TAATCGAACCATATG }\end{array}$ & $\begin{array}{l}\text { AS primer for downstream } \\
\text { flanking region }\end{array}$ \\
\hline & RW185 & TATGAAGGACATGGCTAAAATGAGAATATCAC & S primer for aphA3 \\
\hline & RW273 & $\begin{array}{l}\text { CAATCTGTGACTAAAACAATTCATCCAGTAAAATATAA } \\
\text { TATTTTATTTTC }\end{array}$ & AS primer for aphA3 \\
\hline
\end{tabular}




\section{Methods}

\section{LEAD CONTACT AND MATERIALS AVAILABILITY}

Further information and requests for resources and reagents should be directed to and will be fulfilled by the Lead Contact, Michael Federle (mfederle@uic.edu). This study did not generate new unique reagents.

\section{EXPERIMENTAL MODEL AND SUBJECT DETAILS}

Bacterial strains. S. pyogenes (Group A Streptococcus, GAS) strain NZ131 was used as the parental strain for genetic mutants (constructed as described below). Other GAS strains tested included HSC5, 5448, and MGAS315. GAS were routinely grown without shaking at $37^{\circ} \mathrm{C}$ in Todd-Hewitt $0.2 \%$ yeast extract (THY) broth or on agar plates, or in a chemically defined medium (CDM) containing 1\% (wt/vol) glucose. ${ }^{47}$ To induce Rgg2/3 activation, $100 \mathrm{nM}$ of synthetic SHP pheromone or inactive reverse SHP (revSHP) was added to $S$. pyogenes cultures at $\mathrm{OD}_{600} \sim 0.1$. When appropriate, antibiotics were added at the following concentrations: chloramphenicol $(\mathrm{Cm}), 3 \mu \mathrm{g} / \mathrm{ml}$; erythromycin (Erm), 0.5 $\mu \mathrm{g} / \mathrm{ml}$; kanamycin (Kan), $150 \mu \mathrm{g} / \mathrm{ml}$; spectinomycin (Sp), $100 \mu \mathrm{g} / \mathrm{ml}$. Starter cultures were utilized to minimize differences in lag phase and were prepared as follows: GAS strains of interest were streaked on THY plates containing the appropriate antibiotics. Single clones were isolated and inoculated into THY containing the appropriate antibiotics. After incubation overnight at $37^{\circ} \mathrm{C}$, the cultures were diluted 1:20 into CDM and grown at $37^{\circ} \mathrm{C}$ to mid-exponential phase $\left(\mathrm{OD}_{600} 0.5-0.8\right)$. Lastly, glycerol was added to a final concentration of $20 \%$, and single-use aliquots were stored at $-80^{\circ} \mathrm{C}$. 
Construction of mutant strains and complementation plasmids. All bacterial strains used in this study are described in Table 1. Primers used to construct plasmids for gene deletion or complementation are listed in Table 2. All cloning was done using laboratory E. coli cloning strains such as NEB-5a (New England Biolabs) or BH10c, ${ }^{48}$ with antibiotics added at the following concentrations: $\mathrm{Cm}, 10 \mu \mathrm{g} / \mathrm{ml}$; Erm, $500 \mu \mathrm{g} / \mathrm{ml}$; Sp, $100 \mu \mathrm{g} / \mathrm{ml}$. To construct gene deletions, sequences flanking the gene of interest were amplified by PCR and ligated into a temperature-sensitive plasmid, pFED760, by restriction enzyme digest or Gibson assembly. When necessary, antibiotic resistance markers for kanamycin (aphA3) or chloramphenicol (cat) were cloned between the upstream and downstream flanking regions to generate plasmids for selective allelic replacement. Deletion vectors were electroporated into NZ131 and a two-step temperature dependent selection process was used to isolate mutants of interest. Briefly, cells containing each deletion construct were grown at the permissive temperature, then shifted to $37^{\circ} \mathrm{C}$ and plated on the appropriate antibiotic to select for bacteria in which the plasmid had integrated at one of the flanking regions. After confirmation of plasmid integration by PCR, cells were grown for 50 generations at the permissive temperature to allow the plasmid to recombine out, and loss of antibiotic resistance was used to identify the desired mutants. Genotypes were confirmed by PCR. To construct complementation plasmids for BGC mutants, the genomic region encompassing spy49_0450-0457 and its native promoter, were amplified by PCR and cloned into a multi-copy vector (pLZ12-Sp). For complementation of spy49_0459, the 
gene was amplified by PCR and cloned downstream of sequence containing $~ 70$ bp of the shp3 promoter in an integrating shuttle vector (p7INT/pJC420).

Cell lines. NF- $\mathrm{B}$ reporter macrophages (RAW-Blue ${ }^{\mathrm{TM}}$ InvivoGen) were cultured in DMEM (Gibco) supplemented with 10\% FBS (Gemini, BenchMark), penicillin/streptomycin (Corning) and zeocin (InvivoGen) and RAW264.7 macrophages were maintained in RPMI 1640 (Corning) supplemented with 10\% FBS and P/S. All cell lines were maintained and passaged at $37^{\circ} \mathrm{C}+5 \% \mathrm{CO}_{2}$.

Primary cell culture. BMDM and BMDC were generated from bone marrow precursor cells extracted from femurs and tibiae of 6-8 week-old male or female C57BL/6 mice (Charles River Laboratories).

\section{METHOD DETAILS}

Synthetic pheromone peptides. Synthetic peptides of $95 \%$ purity were purchased from NeoPeptide (Cambridge, MA), reconstituted as $1 \mathrm{mM}$ stocks in dimethyl sulfoxide (DMSO), and stored at $-80^{\circ} \mathrm{C}$. Dilutions for working stocks were made in DMSO and stored at $-20^{\circ} \mathrm{C}$. The SHP3-C8 peptide (SHP) sequence is DIIIVGG, and the reverse peptide (rev-SHP) sequence is GGVIIIID.

In vitro infections. $2.5 \times 10^{5}$ macrophages were seeded into 24 -well tissue culture treated plates (Corning) in $500 \mu \mathrm{L}$ of medium supplemented with penicillin/streptomycin 
the day before infection. The following day, medium was aspirated and replaced with medium without antibiotics. GAS was grown from starter cultures in CDM to $\mathrm{OD}_{600}=0.5$ ( 2-3 hours), then normalized based on OD, washed in PBS, and added to macrophages. Unless otherwise noted, macrophages were inoculated with GAS at a multiplicity of infection of 10:1. Cells were immediately centrifuged at $200 \times \mathrm{g}$ for 5 minutes to equilibrate infection and then incubated at $37^{\circ} \mathrm{C}$ with $5 \% \mathrm{CO}_{2}$. After 30 minutes, extracellular bacteria were killed by replacing with medium containing 100 $\mu \mathrm{g} / \mathrm{ml}$ gentamicin (Gibco). Where applicable, cells were treated with the following TLR agonists from InvivoGen: Lipopolysaccharide (LPS, 100 ng/ml), Heat-Killed Listeria monocytogenes (HKLM, $1 \times 10^{8}$ cells), or CpG oligodeoxynucleotides (ODN1826, 1 $\mu \mathrm{M})$. For experiments with attenuated GAS, bacteria were killed with heat (65C), UV (short wave), or 4\% PFA for 60 minutes. For experiments using GAS supernatants, cells were grown to $\mathrm{OD}_{600} \sim 0.5$ and pelleted, and the supernatants were subsequently filtered $(0.2 \mu \mathrm{m})$ and normalized based on OD. For trans-well experiments, $0.4 \mu \mathrm{m}$ pores (Corning) were used.

For assays where phagocytosis was blocked, macrophages were pre-treated with 0.5 $\mu \mathrm{g} / \mathrm{ml}$ Cytochalasin D (CytD) for 1 hour. After inoculating with GAS for 30 minutes, cells were treated with gentamicin $(400 \mu \mathrm{g} / \mathrm{ml})$ for 30 minutes to kill remaining GAS. After washing three times with PBS to remove the remaining GAS, gentamicin, and CytD, cells were then stimulated with either LPS (100 ng/ml) or GAS (MOI 10). 
Cell viability assay. Cytotoxicity of macrophages after 8 hours of infection was quantified by measuring the release of the enzyme lactate dehydrogenase in cell supernatants using the CytoTox 96 Non-Radioactive Cytotoxicity Assay (Promega) according to the manufacturer's instructions. Percentages were determined by comparing samples with a $100 \%$ lysis control.

NFKB activation assay. RAW Blue macrophages (InvivoGen) with chromosomally integrated NFאB inducible secreted embryonic alkaline phosphatase (SEAP) reporter construct were used to measure activation of NFKB. Cells were maintained in DMEM (Gibco) supplemented with 10\% heat inactivated FBS (Gemini) and penicillin/streptomycin (Corning) and $200 \mu \mathrm{g} / \mathrm{ml}$ zeocin (InvivoGen) in tissue culture treated T25 flasks (Greiner Bio-One). Cells were grown to 60-70\% confluency, washed with PBS, and then passaged using $0.05 \%$ trypsin/0.53 mM EDTA (Corning) to dissociate them from the flasks. Reporter macrophages were counted and seeded the day prior to the experiment in flat bottom 96-well tissue culture treated plates (Corning) at $5 \times 10^{4}$ cells/well. The following day, GAS was added to the wells at a multiplicity of infection of 10:1 and cells were centrifuged for 5 minutes to equilibrate infection. After a 30-minute incubation at $37^{\circ} \mathrm{C}$, the medium was removed and replaced with medium containing $100 \mu \mathrm{g} / \mathrm{ml}$ gentamicin. After $18 \mathrm{~h}$, RAW Blue cell-free supernatants were collected and $50 \mu \mathrm{l}$ was mixed with $150 \mu \mathrm{l}$ of the QUANTI-Blue substrate (InvivoGen) and incubated at $37^{\circ} \mathrm{C}$ for 45 minutes in a flat bottom 96-well plate. Color change was quantified by measuring absorbance at $625 \mathrm{~nm}$ using a Synergy HTX microplate reader (BioTek). 


\section{Generation of Bone Marrow-derived Macrophages and Dendritic Cells. Primary}

murine bone marrow-derived macrophages (BMDMs) and dendritic cells (BMDCs) were differentiated from bone marrow cells collected from the femurs and tibiae of six to eight-week-old male C57BL/6 (Charles River Laboratories). For macrophage differentiation, bone marrow cells were plated in $100 \times 15 \mathrm{~mm}$ petri dishes in $10 \mathrm{~mL}$ DMEM supplemented with 10\% FBS, 1 mM HEPES buffer (Gibco), 1x Penicillin/Streptomycin (Corning) and $10 \mathrm{ng} / \mathrm{ml}$ MCSF (BioLegend) and incubated at $37^{\circ}$ $\mathrm{C}+5 \% \mathrm{CO}_{2}$. On day 3, medium was removed and cells were re-supplemented with 10 $\mathrm{mL}$ fresh medium. On day 7 , the cells were washed gently with PBS and incubated with trypsin for 5 minutes at $37^{\circ} \mathrm{C}$. Cells were then removed by gentle pipetting, counted, and plated at $2.5 \times 10^{5}$ cells per well on 24 well plates or $5 \times 10^{4}$ cells per well on 96 well plates overnight and infected on day 8.

For dendritic cell differentiation, red blood cells were lysed using RBC Lysis Buffer (Tonbo) and following a centrifugation step, cells were counted and plated on 6 well plates in RPMI $+5 \%$ FBS $+20 \mathrm{ng} / \mathrm{ml}$ GM-CSF (BioLegend). Cells were maintained at $37^{\circ} \mathrm{C} 5 \% \mathrm{CO}_{2}$ and supplemented on day 3,6 , and 8 . On day 10 cells were supplemented with medium containing $12.5 \mathrm{ng} / \mathrm{ml}$ GM-CSF. Cells were collected on day 11 and infected on day 12 .

The purity of BMDMs and BMDCs was measured by cell surface staining and flow cytometry. $2.5 \times 10^{5}$ cells were transferred to an Eppendorf tube and resuspended in FACS buffer (PBS $+1 \%$ BSA). Prior to staining, cells were treated with anti-CD16/CD32 (BioLegend) for 15 minutes to block Fc receptors. Cells were then stained for 30 
minutes on ice with anti-CD11b-APC/Fire 750 and anti-F4/80-PE for macrophages or anti-CD11c-Alexa Fluor 647 for dendritic cells (BioLegend). Samples were washed twice and then run on Cytoflex (Beckman Coulter). Isolated cells were determined to be $>90 \%$ pure.

Quantification of cytokines. Cell-free culture supernatants were harvested at 8 hours post infection and frozen at $-20^{\circ} \mathrm{C}$. The levels of murine IL- 6 and TNF- $\alpha$ and human IL6 were measured using ELISA MAX ${ }^{\mathrm{TM}}$ kits (BioLegend) according to the manufacturer's instructions. For murine IFN $\beta$ the DuoSet ELISA kit (R\&D systems) was used.

Measurement of GAS adherence to macrophages. Adherence to RAW264.7 cells was measured after 30 minutes of infection. Cells were gently washed three times with $500 \mu \mathrm{L}$ PBS, followed by incubation with $100 \mu \mathrm{L}$ trypsin for 5 minutes at $37^{\circ} \mathrm{C}$ and then addition of $400 \mu \mathrm{L} 0.1 \%$ saponin in sterile water for $1-2$ minutes until cells appeared lysed under the microscope. Serial dilutions were plated on THY agar plates and CFUs were enumerated after overnight incubation at $37^{\circ} \mathrm{C}$ with $5 \% \mathrm{CO}_{2}$.

\section{QUANTIFICATION AND STATISTICAL ANALYSIS}

Data were statistically analyzed using GraphPad Prism v.7.0b. Data were analyzed using ordinary one-way ANOVA followed by Tukey's multiple comparisons test or twoway ANOVA followed by Sidak's multiple comparisons test and deemed significant at * $p$ $<0.05 ;{ }^{* *} p<0.005 ;{ }^{* * *} p<0.001 ;{ }^{* * *} p<0.0001$. ns is used to denote non-significant comparisons. 
bioRxiv preprint doi: https://doi.org/10.1101/2020.12.03.411157 this version posted December 4, 2020. The copyright holder for this preprint (which was not certified by peer review) is the author/funder, who has granted bioRxiv a license to display the preprint in perpetuity. It is made available under aCC-BY-NC-ND 4.0 International license.

DATA AND CODE AVAILABILITY

This study did not generate/analyze datasets/code. 


\section{References}

1. Jimenez, J. C. \& Federle, M. J. Quorum sensing in group A Streptococcus. Front. Cell. Infect. Microbiol. 4, 127 (2014).

2. Carapetis, J. R., Steer, A. C., Mulholland, E. K. \& Weber, M. The global burden of group A streptococcal diseases. Lancet Infect Dis 5, 685-694 (2005).

3. Chang, J. C., LaSarre, B., Jimenez, J. C., Aggarwal, C. \& Federle, M. J. Two group A streptococcal peptide pheromones act through opposing Rgg regulators to control biofilm development. PLoS Pathog. 7, e1002190 (2011).

4. Gogos, A., Jimenez, J. C., Chang, J. C., Wilkening, R. V. \& Federle, M. J. A quorum sensing-regulated protein binds cell-wall components and enhances lysozyme resistance in Streptococcus pyogenes. J. Bacteriol. (2018).

5. Goldmann, O., Rohde, M., Chhatwal, G. S. \& Medina, E. Role of macrophages in host resistance to group A streptococci. Infect. Immun. 72, 2956-2963 (2004).

6. Mishalian, I. et al. Recruited macrophages control dissemination of group A Streptococcus from infected soft tissues. J. Immunol. 187, 6022-6031 (2011).

7. Loof, T. G., Rohde, M., Chhatwal, G. S., Jung, S. \& Medina, E. The contribution of dendritic cells to host defenses against Streptococcus pyogenes. J. Infect. Dis. 196, 1794-1803 (2007).

8. Navarini, A. A. et al. Innate immune-induced depletion of bone marrow neutrophils aggravates systemic bacterial infections. Proc. Natl. Acad. Sci. U. S. A. 106, 7107-7112 (2009).

9. Goldmann, O. et al. Transcriptome analysis of murine macrophages in response to infection with Streptococcus pyogenes reveals an unusual activation program. Infect. Immun. 75, 4148-4157 (2007).

10. Loof, T. G., Goldmann, O. \& Medina, E. Immune recognition of Streptococcus pyogenes by dendritic cells. Infect. Immun. 76, 2785-2792 (2008).

11. Loof, T. G., Goldmann, O., Gessner, A., Herwald, H. \& Medina, E. Aberrant inflammatory response to Streptococcus pyogenes in mice lacking myeloid differentiation factor 88. Am. J. Pathol. 176, 754-763 (2010).

12. Gratz, N. et al. Group A streptococcus activates type I interferon production and MyD88-dependent signaling without involvement of TLR2, TLR4, and TLR9. J. Biol. Chem. 283, 19879-19887 (2008).

13. Gratz, N. et al. Type I Interferon Production Induced by Streptococcus pyogenes-Derived Nucleic Acids Is Required for Host Protection. PLOS Pathogens 7, e1001345 (2011).

14. Chang, J. C., Jimenez, J. C. \& Federle, M. J. Induction of a quorum sensing pathway by environmental signals enhances group A streptococcal resistance to lysozyme. Mol. Microbiol. 97, 1097-1113 (2015).

15. Kang, S. O. et al. Thermoregulation of capsule production by Streptococcus pyogenes. PLoS ONE 7, e37367 (2012).

16. Moura-Alves, P. et al. Host monitoring of quorum sensing during Pseudomonas aeruginosa infection. Science 366 (2019).

17. LaPenta, D., Rubens, C., Chi, E. \& Cleary, P. P. Group A streptococci efficiently invade human respiratory epithelial cells. PNAS 91, 12115-12119 (1994).

18. O'Neill, A. M., Thurston, T. L. M. \& Holden, D. W. Cytosolic Replication of Group A Streptococcus in Human Macrophages. MBio 7, 20 (2016). 
19. Greco, R. et al. Invasion of cultured human cells by Streptococcus pyogenes. Res. Microbiol. 146, 551-560 (1995).

20. Walker, M. J. et al. Disease manifestations and pathogenic mechanisms of Group A Streptococcus. Clin. Microbiol. Rev. 27, 264-301 (2014).

21. Valderrama, J. A. \& Nizet, V. Group A Streptococcus encounters with host macrophages. Future Microbiol. 13, 119-134 (2018).

22. Aggarwal, C. et al. Identification of Quorum-Sensing Inhibitors Disrupting Signaling between Rgg and Short Hydrophobic Peptides in Streptococci. MBio 6, 393 (2015).

23. Le Breton, Y. et al. Genome-wide identification of genes required for fitness of group A Streptococcus in human blood. Infect. Immun. 81, 862-875 (2013).

24. Kizy, A. E. \& Neely, M. N. First Streptococcus pyogenes signature-tagged mutagenesis screen identifies novel virulence determinants. Infect. Immun. 77, 1854-1865 (2009).

25. Toukoki, C., Gold, K. M., Mclver, K. S. \& Eichenbaum, Z. MtsR is a dual regulator that controls virulence genes and metabolic functions in addition to metal homeostasis in the group A streptococcus. Mol. Microbiol. 76, 971-989 (2010).

26. Liu, X. et al. Genome-wide screening reveals the genetic determinants of an antibiotic insecticide in Bacillus thuringiensis. J. Biol. Chem. 285, 39191-39200 (2010).

27. Reddick, L. E. \& Alto, N. M. Bacteria fighting back: how pathogens target and subvert the host innate immune system. Mol. Cell 54, 321-328 (2014).

28. Madden, J. C., Ruiz, N. \& Caparon, M. Cytolysin-mediated translocation (CMT): a functional equivalent of type III secretion in gram-positive bacteria. Cell 104, 143-152 (2001).

29. Bastiat-Sempe, B., Love, J. F., Lomayesva, N. \& Wessels, M. R. Streptolysin O and NAD-glycohydrolase prevent phagolysosome acidification and promote group A Streptococcus survival in macrophages. MBio 5, 1690 (2014).

30. Yokoyama, R. et al. Staphylococcal superantigen-like protein 3 binds to the Toll-like receptor 2 extracellular domain and inhibits cytokine production induced by Staphylococcus aureus, cell wall component, or lipopeptides in murine macrophages. Infect. Immun. 80, 2816-2825 (2012).

31. Koymans, K. J. et al. Structural basis for inhibition of TLR2 by staphylococcal superantigen-like protein 3 (SSL3). Proc. Natl. Acad. Sci. U. S. A. 112, 11018-11023 (2015).

32. Askarian, F. et al. A Staphylococcus aureus TIR domain protein virulence factor blocks TLR2-mediated NF-kB signaling. J Innate Immun 6, 485-498 (2014).

33. Hancz, D. et al. Streptolysin O Induces the Ubiquitination and Degradation of Pro-IL-1ß. J Innate Immun 11, 457468 (2019).

34. Edwards, R. J. et al. Specific C-terminal cleavage and inactivation of interleukin-8 by invasive disease isolates of Streptococcus pyogenes. J. Infect. Dis. 192, 783-790 (2005).

35. Gogos, A. \& Federle, M. J. Colonization of the murine oropharynx by Streptococcus pyogenes is governed by the Rgg2/3 quorum sensing system. Infect. Immun. (2020).

36. Wilkening, R. V., Chang, J. C. \& Federle, M. J. PepO, a CovRS-controlled endopeptidase, disrupts Streptococcus pyogenes quorum sensing. Mol. Microbiol. 99, 71-87 (2016). 
37. Chatellier, S. et al. Genetic relatedness and superantigen expression in group A streptococcus serotype M1 isolates from patients with severe and nonsevere invasive diseases. Infect Immun 68, 3523-3534 (2000).

38. Hanski, E., Horwitz, P. A. \& Caparon, M. G. Expression of protein F, the fibronectin-binding protein of Streptococcus pyogenes JRS4, in heterologous streptococcal and enterococcal strains promotes their adherence to respiratory epithelial cells. Infect Immun 60, 5119-5125 (1992).

39. Port, G. C., Paluscio, E. \& Caparon, M. G. Complete Genome Sequence of emm Type 14 Streptococcus pyogenes Strain HSC5. Genome Announc 1 (2013).

40. Musser, J. M. et al. Streptococcus pyogenes causing toxic-shock-like syndrome and other invasive diseases: clonal diversity and pyrogenic exotoxin expression. Proc Natl Acad Sci U S A 88, 2668-2672 (1991).

41. Beres, S. B. et al. Genome sequence of a serotype M3 strain of group A Streptococcus: phage-encoded toxins, the high-virulence phenotype, and clone emergence. Proc. Natl. Acad. Sci. U. S. A. 99, 10078-10083 (2002).

42. McShan, W. M. et al. Genome sequence of a nephritogenic and highly transformable M49 strain of Streptococcus pyogenes. J. Bacteriol. 190, 7773-7785 (2008).

43. Cho, K. H., Port, G. C. \& Caparon, M. Genetics of Group A Streptococci. Microbiol Spectr 7 (2019).

44. McShan, W., McLaughlin, R., Nordstrand, A. \& Ferretti, J. Vectors containing streptococcal bacteriophage integrases for site-specific gene insertion. Methods Cell Sci 20, $51-57$ (1998).

45. Mashburn-Warren, L., Morrison, D. A. \& Federle, M. J. A novel double-tryptophan peptide pheromone controls competence in Streptococcus spp. via an Rgg regulator. Mol. Microbiol. 78, 589-606 (2010).

46. Husmann, L. K., Scott, J. R., Lindahl, G. \& Stenberg, L. Expression of the Arp protein, a member of the M protein family, is not sufficient to inhibit phagocytosis of Streptococcus pyogenes. Infect Immun 63, 345-348 (1995).

47. van de Rijn, I. \& Kessler, R. E. Growth characteristics of group A streptococci in a new chemically defined medium. Infect Immun 27, 444-448 (1980).

48. Howell-Adams, B. \& Seifert, H. S. Molecular models accounting for the gene conversion reactions mediating gonococcal pilin antigenic variation. Mol Microbiol 37, 1146-1158 (2000). 
Figure 1
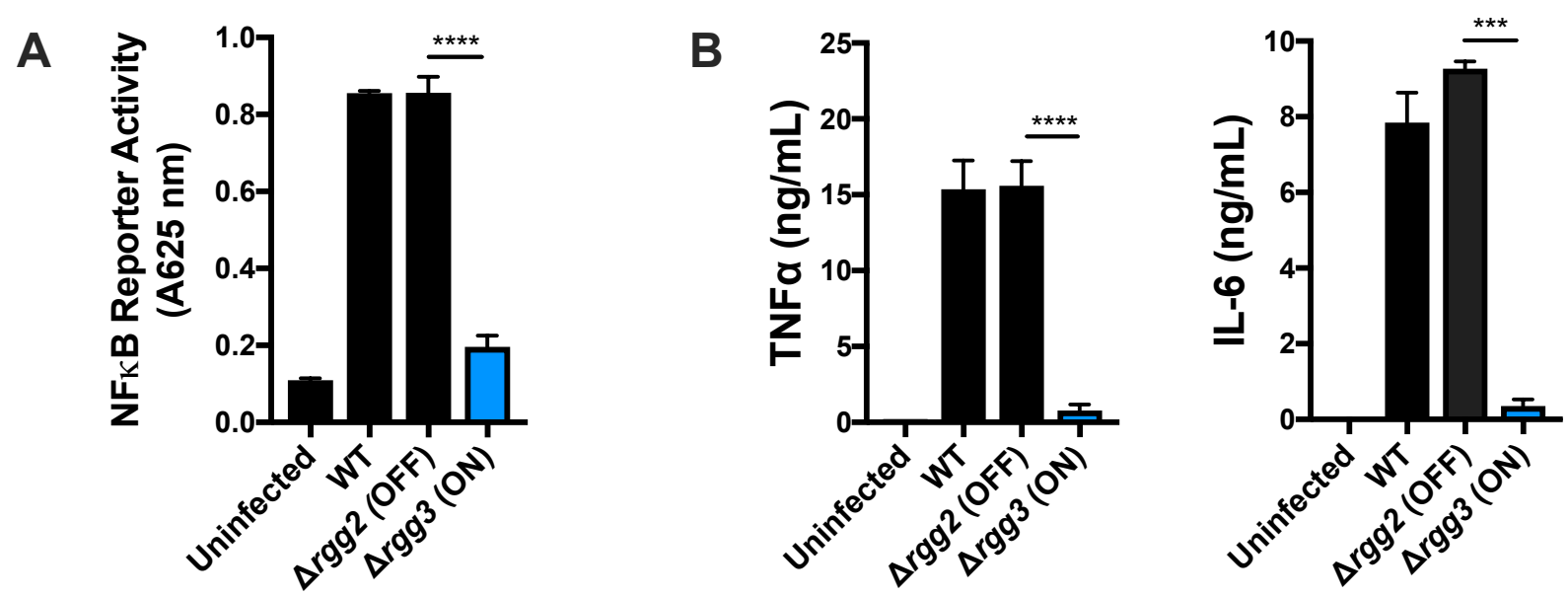

C
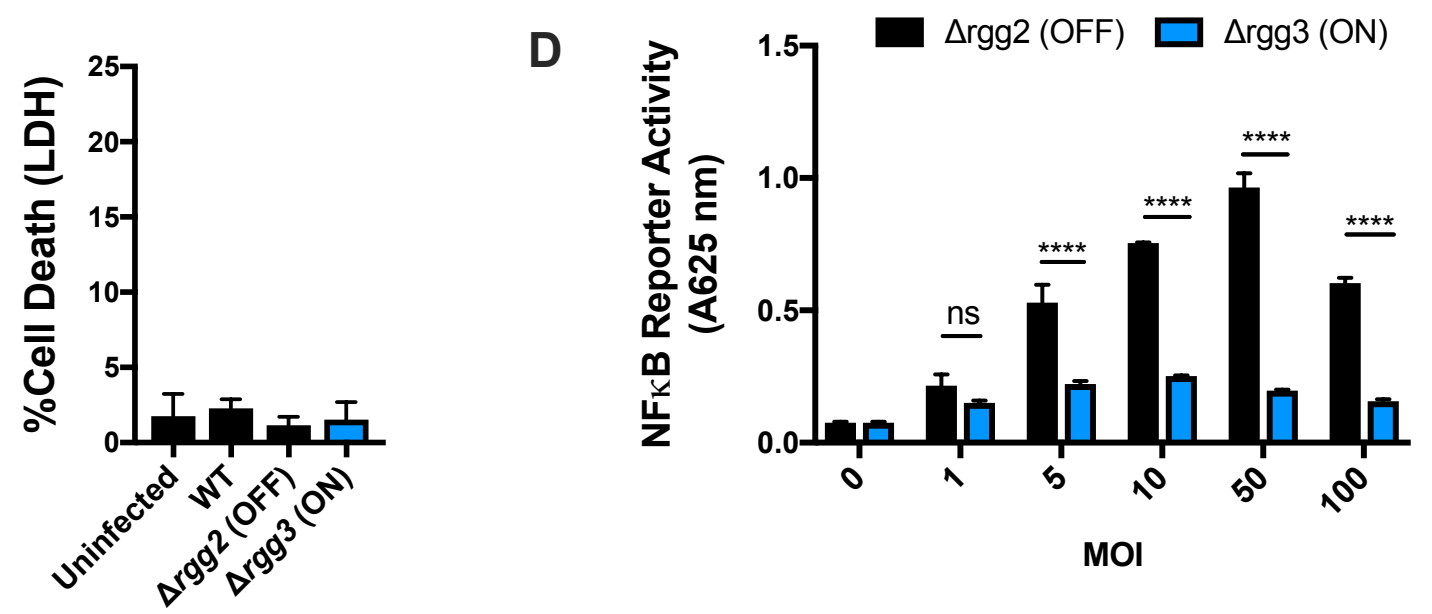

E
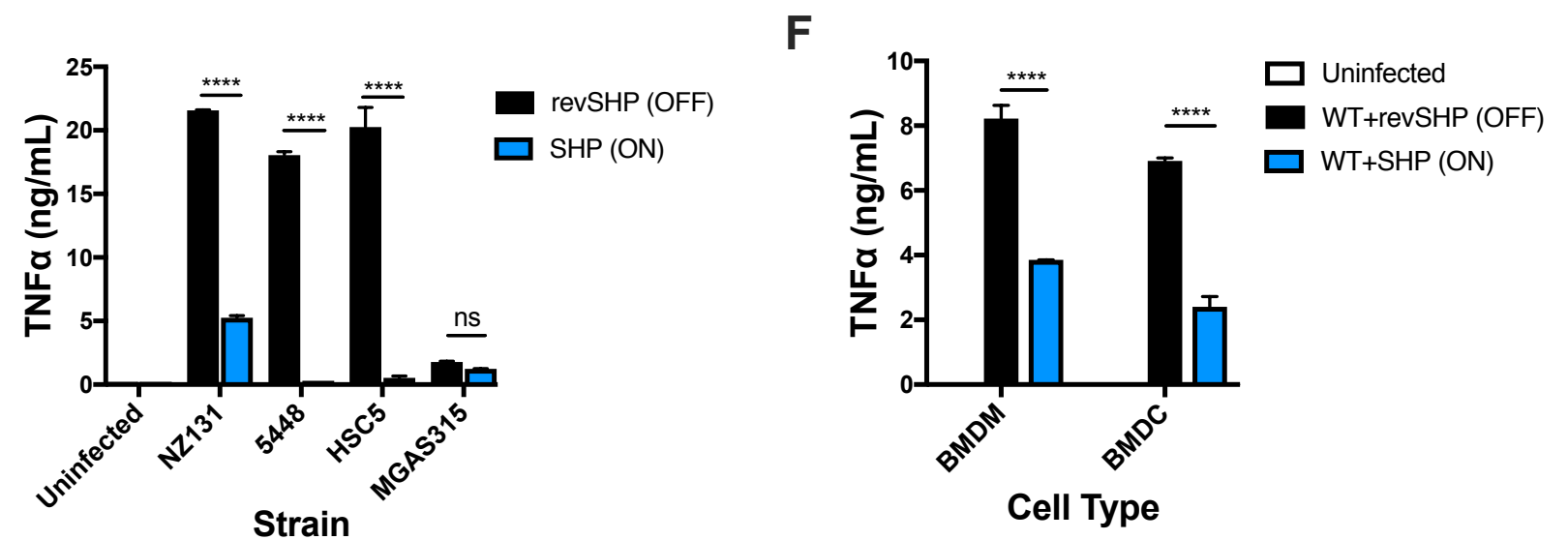
Figure 2

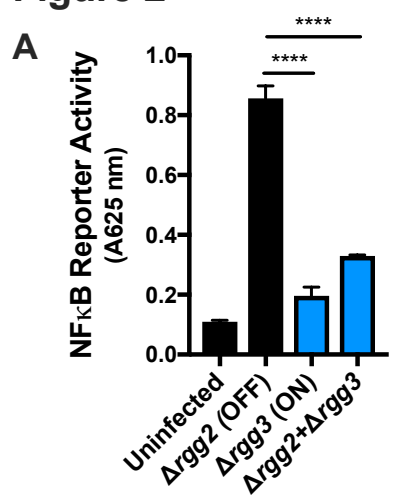

C

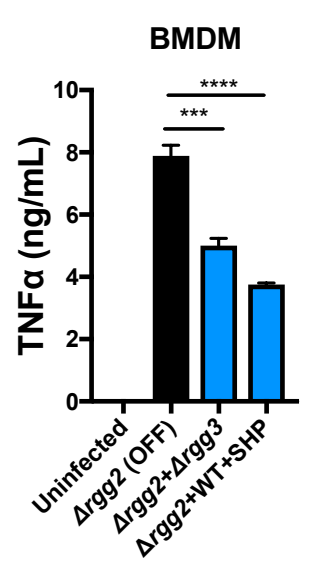

B
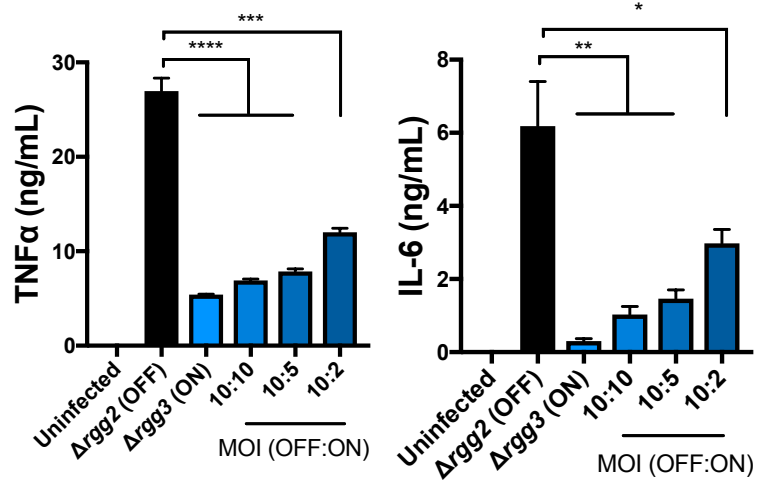
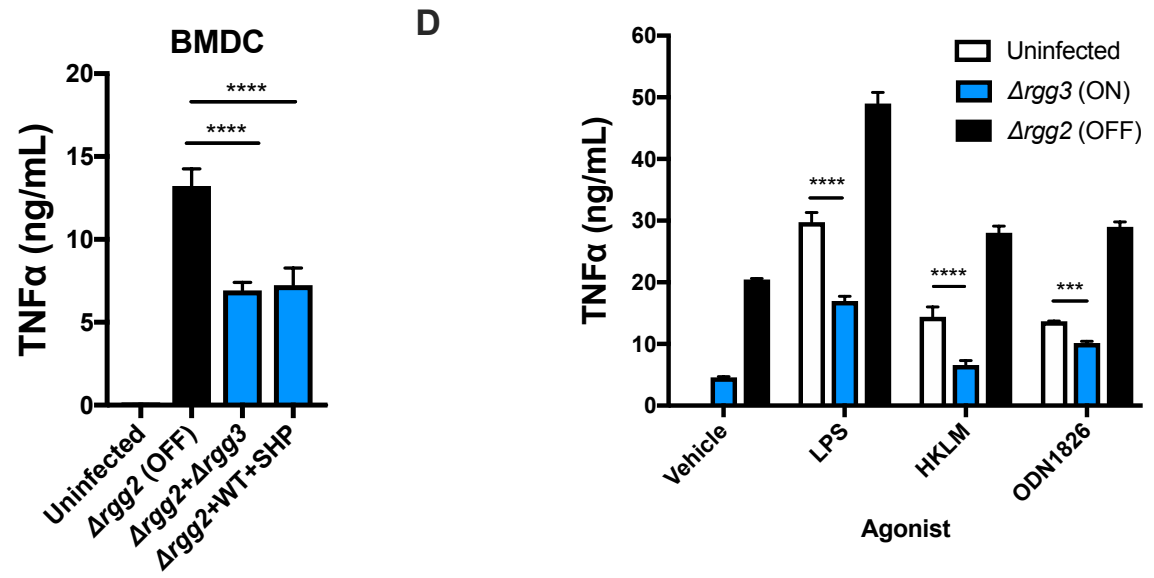
Figure 3

A

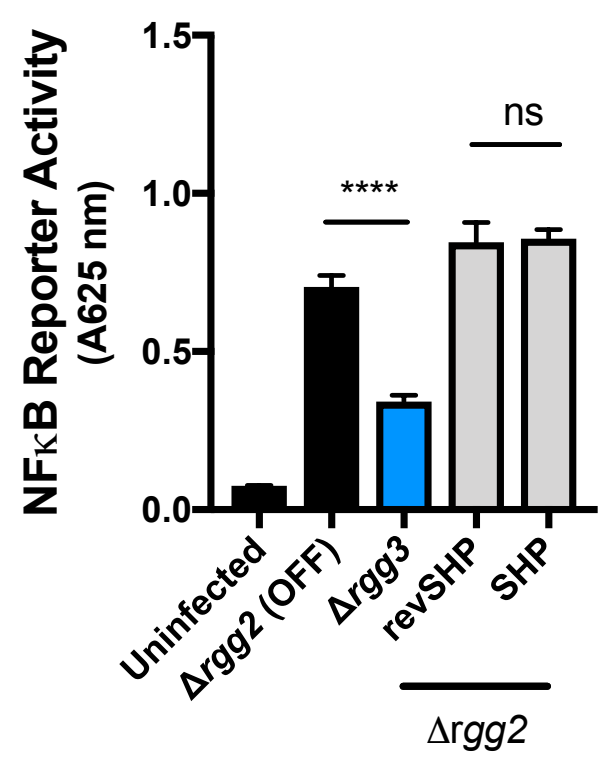

B
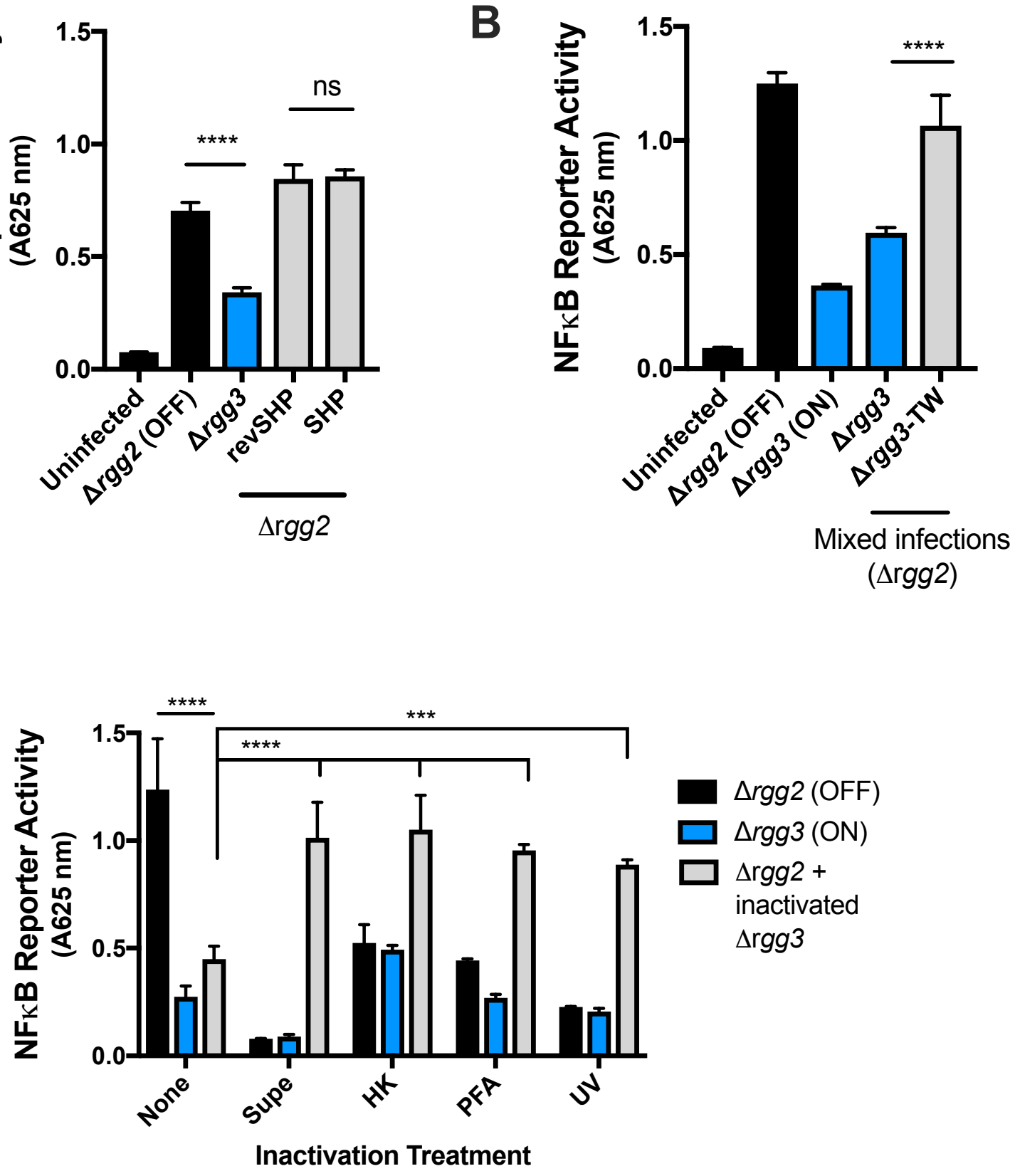
Figure 4

A

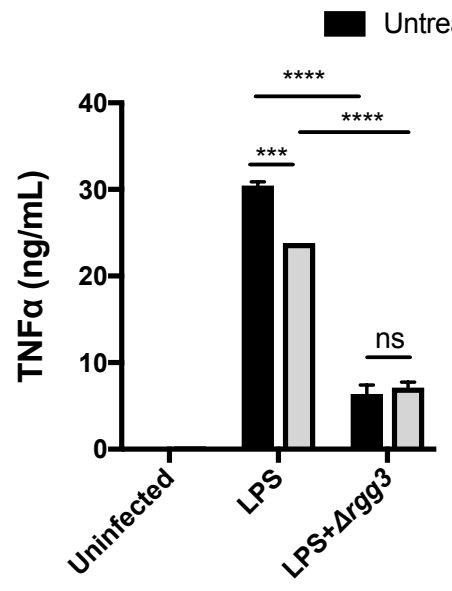

B

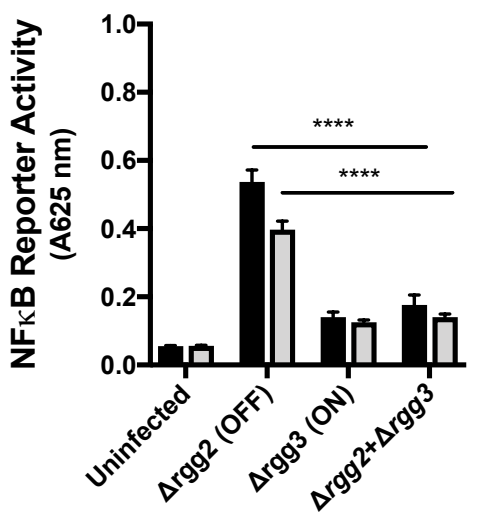

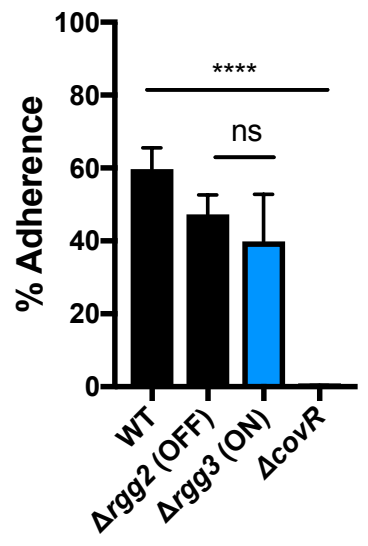




\section{Figure 5}

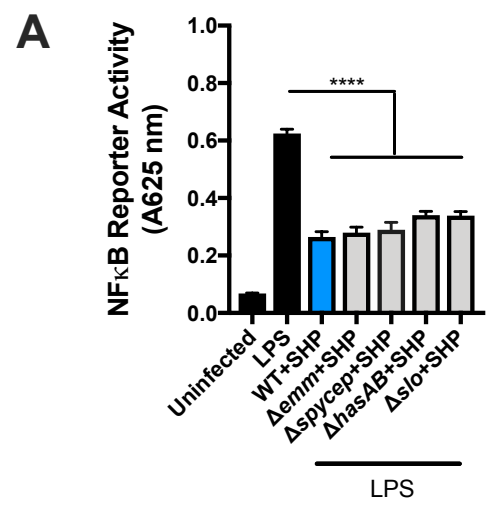

B

C
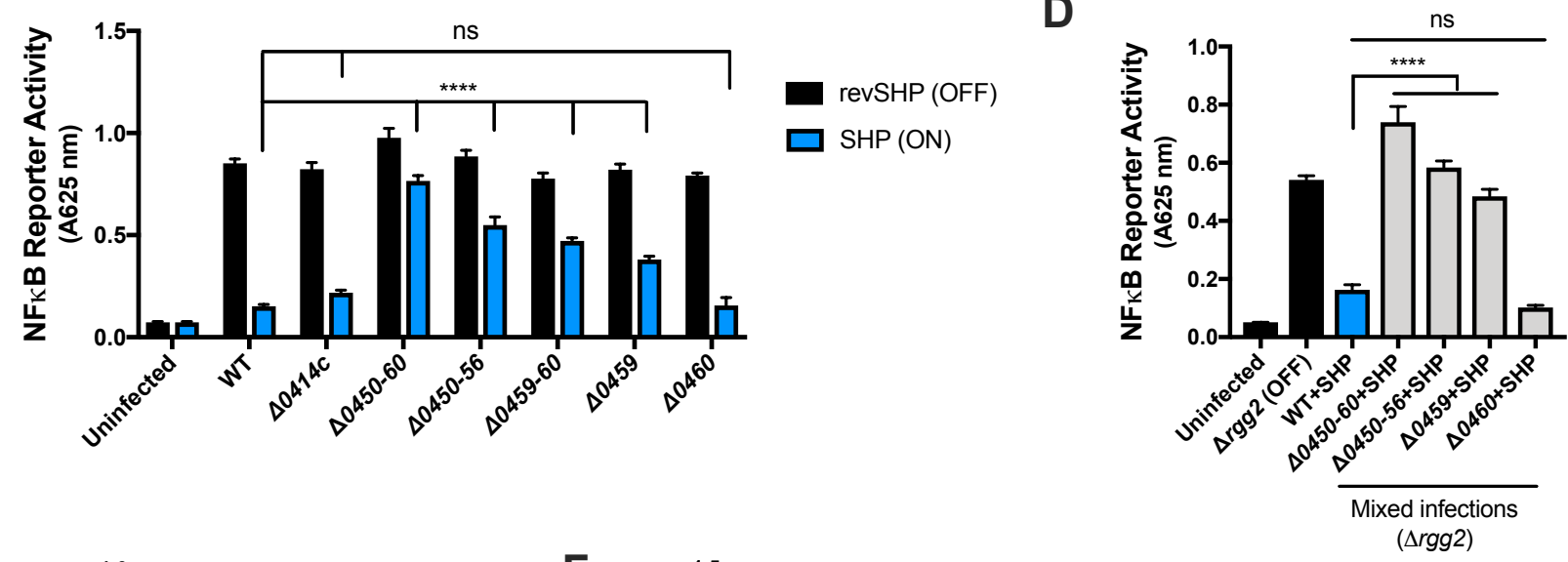

E

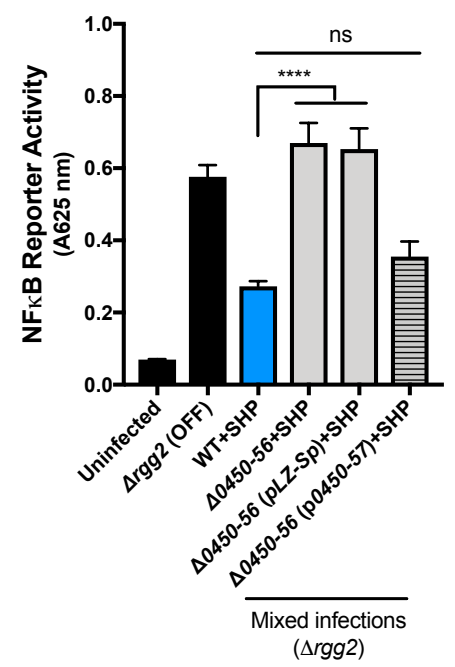

F

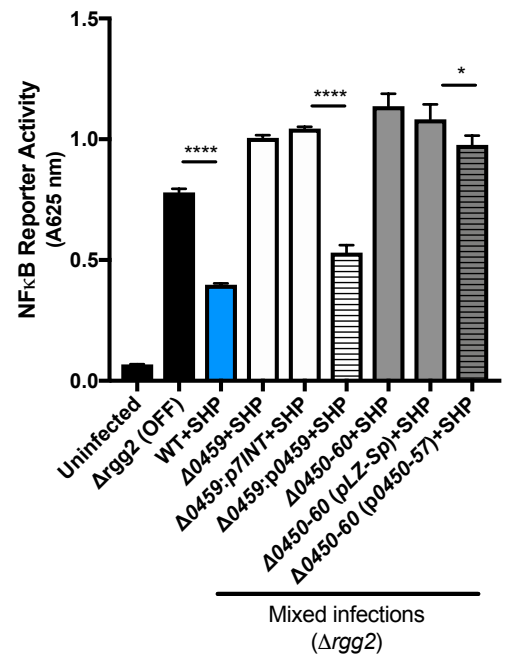




\section{Figure 6}

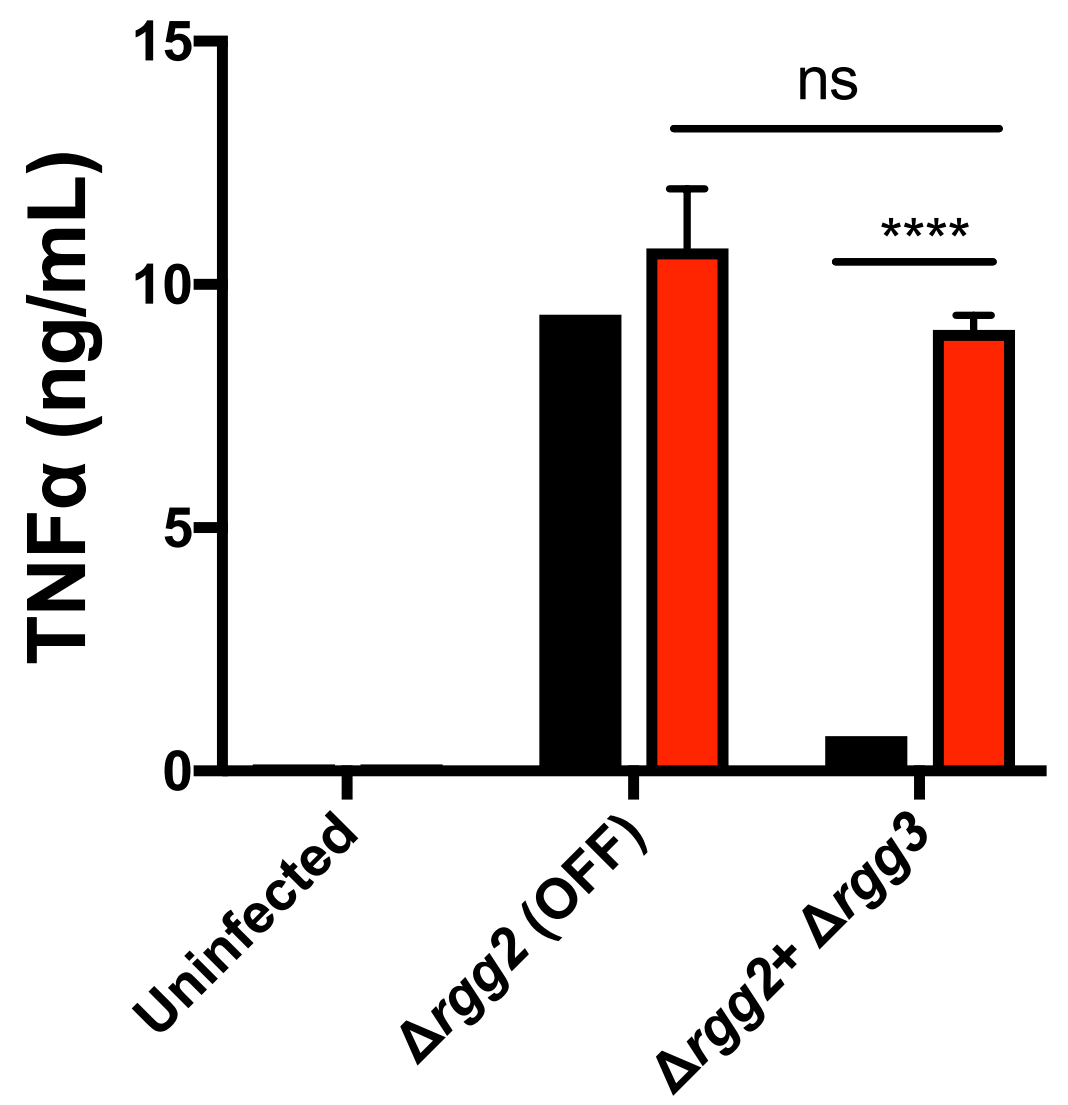

Untreated Valspodar 